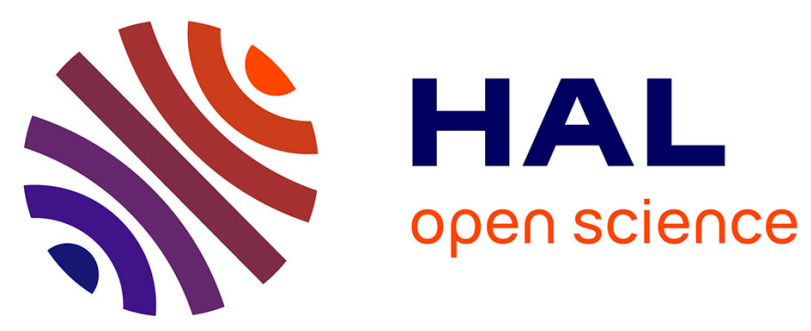

\title{
Seafloor sealing, doming, and collapse associated with gas seeps and authigenic carbonate structures at Venere mud volcano, Central Mediterranean
}

Markus Loher, Yann Marcon, Thomas Pape, Miriam Römer, Paul

Wintersteller, Christian dos Santos Ferreira, Daniel Praeg, Marta Torres,

Heiko Sahling, Gerhard Bohrmann

\section{To cite this version:}

Markus Loher, Yann Marcon, Thomas Pape, Miriam Römer, Paul Wintersteller, et al.. Seafloor sealing, doming, and collapse associated with gas seeps and authigenic carbonate structures at Venere mud volcano, Central Mediterranean. Deep Sea Research Part I: Oceanographic Research Papers, 2018, 137, pp.76-96. 10.1016/j.dsr.2018.04.006 . hal-02157573

\section{HAL Id: hal-02157573 \\ https://hal.science/hal-02157573}

Submitted on 17 Jun 2019

HAL is a multi-disciplinary open access archive for the deposit and dissemination of scientific research documents, whether they are published or not. The documents may come from teaching and research institutions in France or abroad, or from public or private research centers.
L'archive ouverte pluridisciplinaire HAL, est destinée au dépôt et à la diffusion de documents scientifiques de niveau recherche, publiés ou non, émanant des établissements d'enseignement et de recherche français ou étrangers, des laboratoires publics ou privés. 


\section{Author's Accepted Manuscript}

Seafloor sealing, doming, and collapse associated with gas seeps and authigenic carbonate structures at Venere mud volcano, Central Mediterranean

Markus Loher, Yann Marcon, Thomas Pape, Miriam Römer, Paul Wintersteller, Christian dos Santos Ferreira, Daniel Praeg, Marta Torres, Heiko Sahling, Gerhard Bohrmann

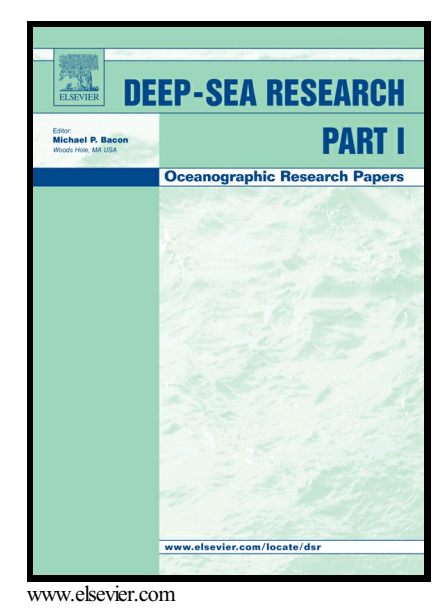

PII: $\quad$ S0967-0637(17)30325-4

DOI: $\quad$ https://doi.org/10.1016/j.dsr.2018.04.006

Reference: DSRI2903

To appear in: Deep-Sea Research Part I

Received date: 17 October 2017

Revised date: 13 March 2018

Accepted date: 12 April 2018

Cite this article as: Markus Loher, Yann Marcon, Thomas Pape, Miriam Römer, Paul Wintersteller, Christian dos Santos Ferreira, Daniel Praeg, Marta Torres, Heiko Sahling and Gerhard Bohrmann, Seafloor sealing, doming, and collapse associated with gas seeps and authigenic carbonate structures at Venere mud volcano, Central Mediterranean, Deep-Sea Research Part I, https://doi.org/10.1016/j.dsr.2018.04.006

This is a PDF file of an unedited manuscript that has been accepted for publication. As a service to our customers we are providing this early version of the manuscript. The manuscript will undergo copyediting, typesetting, and review of the resulting galley proof before it is published in its final citable form. Please note that during the production process errors may be discovered which could affect the content, and all legal disclaimers that apply to the journal pertain. 


\section{Seafloor sealing, doming, and collapse associated with gas seeps and authigenic carbonate structures at Venere mud volcano, Central Mediterranean}

Markus Loher ${ }^{1, *}$; Yann Marcon ${ }^{1}$; Thomas Pape ${ }^{1}$; Miriam Römer ${ }^{1}$; Paul Wintersteller ${ }^{1}$, Christian dos Santos Ferreira'; Daniel Praeg²; Marta Torres ${ }^{3}$; Heiko Sahling ${ }^{1}$; Gerhard Bohrmann ${ }^{1}$

${ }^{1}$ MARUM - Center for Marine Environmental Sciences and Department of Geosciences at University of Bremen, Klagenfurter Str., 28359 Bremen, Germany

${ }^{2}$ OGS (Istituto Nazionale di Oceanografia e di Geofisica Sperimentale), Borgo Grotta Gigante 42/c, Sgonico, 34010 Trieste, Italy; present address: Institute of Petroleum and Natural Resources, PUCRS, Av. Ipiranga, 6681, 90619-900 Porto Alegre, RS, Brazil AND Géoazur (UMR7329 CNRS), 250 Rue Albert Einstein, 06560 Valbonne, France

${ }^{3}$ College of Earth, Ocean, and Atmospheric Sciences, Oregon State University, 104 CEOAS Administration Building, Corvallis, OR 97331-5503, USA

*Corresponding author e-mail: mloher@marum.de

\section{Abstract}

Methane release from the seafloor is commonly associated with chemosynthesis-based coldseep ecosystems that facilitate the precipitation of authigenic carbonates. It has been proposed that carbonate growth results in self-sealing, but little is known regarding the evolution of cold-seep structures in relation to fluid migration pathways. This study investigates structures resulting from gas seepage along ring faults peripheral to Venere mud volcano (1600 m water depth), based on multibeam bathymetry and seafloor backscatter data collected by an autonomous underwater vehicle, together with photomosaics, video observations, and samples obtained by a remotely operated vehicle. Sites of focused fluid flow are identified by gas bubble streams rising from the seafloor while anaerobic oxidation of methane over wider areas is indicated by the occurrence of chemosynthesis-based organisms (microbial mats, vesicomyid clams, vestimentiferan tube worms). At some sites, 
flakes of gas hydrate were observed in the water column during sampling. A range of carbonate structures exists at these sites: 1) flat and extensive pavements; 2) mounds with disseminated nodules or cm-thick crusts; 3) fractured mounds with exposed, dm-thick crusts; and 4) seafloor depressions lined by dm-thick crusts. The mineralogy and stable carbon isotopic compositions of the carbonates are consistent with anaerobic oxidation of methane from thermogenic sources, and possible near-seabed influence of gas hydrate formation and dissolution. The seafloor expressions of seepage are inferred to be controlled by the interaction of fluid flow due to carbonate precipitation and gas hydrate formation. A conceptual model for mound development is proposed in the context of the known timescales of seep-colonization and rates of carbonate precipitation: $(A)$ the onset of hydrocarbon-rich fluid-seepage through hemipelagic sediments leads to (B) the establishment of microbial mats on flat seafloor over decadal timescales and is followed by (C) the growth of pavements cemented by carbonates that seal the seafloor; over longer timescales (centuries to millennia), carbonate growth and subsurface gas hydrate formation/dissolution lead to (D) upward doming and fracturing of carbonate mounds, resealing and stacking of carbonates and in some cases to (E) their collapse to form depressions. Gas migration through fractures in the carbonates allows resealing and fuels AOM to provide habitats for chemosynthesis-based fauna. This evolutionary scenario is argued to be broadly applicable to the development of ruptured mounds and collapse features described at other seepage sites in the eastern Mediterranean Sea and elsewhere.

Keywords: mud volcano; cold seep; carbonate seal; photomosaic; tube worms; Calabrian Accretionary Prism

\section{Introduction}

The migration, accumulation, and seepage of hydrocarbon-rich fluids in marine sediments is an important process for material cycling on continental margins, both through its influence on sediment stability and its role in carbon cycling (Dillon et al. 2001; Römer et al. 2014; Koch et al. 2015). The focused seepage of methane-rich fluids sustains the growth of microbially-mediated cold seep systems, associated with chemosynthesis-based organisms and the precipitation of authigenic carbonates (Paull et al. 1984; Sibuet and Olu 1998; Aloisi et al. 2000). The development of cold seeps has been linked to a variety of seafloor morphologies, including low-relief carbonate pavements (Himmler et al. 2011; Römer et al. 
2014), seabed mounds (Bahr et al. 2007; Buerk et al. 2010; Römer et al. 2014; Koch et al. 2015), pockmarks (Hovland 2002), and mud volcanoes (MVs; e.g. Zitter et al. (2005)). Submarine MVs result from the extrusion of mud breccia, a mixture of clay-rich sediments, rock clasts, and fluids, typically accompanied by the emission of gas with methane contents $>70$ vol-\% (Kopf 2002). In such settings, methane-rich mud breccia deposits have been found covered by carbonate crusts and settled by chemosynthesis-based organisms (Aloisi et al. 2000; Huguen et al. 2005). Seafloor investigations and mapping at MVs indicate that cold seep ecosystems are often organized concentrically around the extrusive centers of MVs (Zitter et al. 2005; de Beer et al. 2006) or occur specifically at sites where gas is actively supplied from below (Loher et al. 2018).

Sites of seafloor fluid discharge can often be identified as distinctive positive or negative morphologies that result from carbonate precipitation, gas accumulations, sediment deformation or extrusion, or by a combination of these processes (Buerk et al. 2010; Römer et al. 2012; Ceramicola et al. 2014; Römer et al. 2014; Koch et al. 2015). Gas bubble emissions from the seafloor become visible in hydroacoustic echograms as high-backscatter signals in the water column (here referred to as flares), and are reliable indicators of active seepage (Nikolovska et al. 2008; Philip et al. 2016; Römer et al. 2016). Fluid flow at cold seeps also involves the upward transport of methane in dissolved form. Dissolved methane is oxidized by microbes, either aerobically near the sediment-water interface, or anaerobically in the subsurface (Barnes and Goldberg 1976; Reeburgh 1976). The sulfatedependent anaerobic oxidation of methane (AOM) leads to an increase in dissolved sulfide, which in turn provides energy for chemosynthetic symbionts and allows the establishment of oasis-type ecosystems at cold seep sites (Paull et al. 1984; Sibuet and Olu 1998; Sahling et al. 2002). AOM further increases the pore water alkalinity, promoting the precipitation of authigenic carbonates (Aloisi et al. 2000; Luff et al. 2004; Bayon et al. 2009; Himmler et al. 2011; Himmler et al. 2015). Methane-derived authigenic carbonate is characterized by ${ }^{13} \mathrm{C}$ depleted carbon and its presence in the sediment record may document episodes of past fluid flow (Teichert et al. 2003; Naehr et al. 2007; Bayon et al. 2009; Himmler et al. 2015; Crémière et al. 2016). It is in the nature of cold seeps that fluid flow intensity is highly variable both spatially and temporally (e.g. Römer et al. (2016)) and it has been suggested that carbonate mineralogies, lipid biomarkers, and carbonate-associated sulfate can be used to reconstruct seepage intensity (Pape et al. 2005; Birgel et al. 2011; Feng et al. 2016).

Carbonate precipitation in the pore space reduces the overall permeability of sediments (Bahr et al. 2007) and over time has the potential to seal fluid migration pathways (Hovland 2002; Bayon et al. 2009). Sediment permeability can also be reduced by the formation of gas 
hydrates (Sassen et al. 2004; Römer et al. 2012), which form within the upper hundreds of meters below seafloor where the required pressure, temperature, and salinity conditions are met and where pore fluids are oversaturated in methane (Kvenvolden 1988; Bohrmann et al. 1998; Pape et al. 2010; Römer et al. 2012). The growth of gas hydrates in response to a supply of hydrocarbon-rich fluids may modify migration pathways, leading to localized methane undersaturation and hydrate dissolution, a process argued to contribute to sediment deformation and pockmark formation (Sultan et al. 2014). As bottom waters are undersaturated in methane, gas hydrates that have formed in near-surface sediments will undergo dissolution and provide a diffusive methane supply from the seafloor (Sahling et al. 2002; Sassen et al. 2004).

The occurrence of carbonate crusts, biological communities, the presence of free gas or gas hydrates at or near the seafloor, as well as mud breccia deposits, or a combination of these are common expressions of cold seeps (Aloisi et al. 2000). In swath sonar data, such features are typically associated with seafloor backscatter signatures (in this study simply referred to as backscatter) that are of higher intensity relative to the surrounding seafloor (Volgin and Woodside 1996; Klaucke et al. 2006). Hydroacoustic observations of gas flares at the rims of high backscatter patches have been inferred to indicate gas bubble release along the edges of carbonate pavements (Naudts et al. 2008; Dupré et al. 2010; Römer et al. 2014) or shallow gas hydrate accumulations (Römer et al. 2012) inferred to form seals above the main upward fluid migration pathways. In several studies evolutionary schemes for cold seeps involving self-sealing (Hovland 2002; Bayon et al. 2009) or in which seal formation is followed by fracturing (Bahr et al. 2010) and pockmark formation (Matsumoto 1990; Marcon et al. 2014a) have been proposed. However, these processes remain poorly understood and information on the proposed evolutionary schemes often remains limited by a lack of detailed visual ground-truthing of the spatial distribution and variability of seafloor features in cold seep settings.

An improved understanding of the spatial and temporal evolution of cold seeps is thus important to constrain the functioning of the deep-sea ecological hotspots and how subsurface gas migration and accumulation may affect sediment stability and pose hazards for seafloor operations. Investigations focusing on seepage-influenced seafloor morphologies necessitate accurate mapping and require state-of-the-art echosounder technologies, ideally mounted on autonomous or remotely-operated underwater vehicles (AUVs or ROVs; (Römer et al. 2012; Pierre et al. 2014; Römer et al. 2014; Philip et al. 2016; Römer et al. 2016)). Visual documentation of offshore cold seeps is usually restricted to narrow strips or areas of a few $\mathrm{m}^{2}$, where video sleds, submersibles, or ROVs have crossed larger targets (Zitter et al. 
2005; Naudts et al. 2008; Sahling et al. 2008; Paull et al. 2015; Panieri et al. 2017). To visualize an entire fluid emission system and the seafloor manifestations resulting from ongoing or past seepage requires the systematic acquisition of geo-referenced photomosaics (Marcon et al. 2013b). To date, only a few such studies exist for cold seep systems (Marcon et al. 2014a) or and only partially for seepage sites at mud volcanoes (Jerosch et al. 2007).

The aim of this study is to provide new insights into the development of cold-seep environments based on geological, visual, and hydroacoustic data from cold seeps associated with gas release along the periphery of Venere MV, located in the Calabrian Accretionary Prism (CAP) in the central Mediterranean Sea (Fig. 1a). Multibeam bathymetric and backscatter data obtained using AUVs in 2014 and 2016 (Loher et al. 2018) are integrated with seafloor photomosaics at four sites, which provide the resolution (cm-scale) and areal extent (several hundred $\mathrm{m}^{2}$ ) necessary to establish the spatial extent of seafloor affected by seepage. The observations are ground-truthed by interactive observations made with ROVs and geochemical analyses that provide information on carbonate compositions and fluid sources. The results provide new information on the possible seafloor expressions of seepage and insights into the dynamics of methane release from the seafloor to the hydrosphere. A conceptual model of the evolution of submarine cold seeps over decadal to millennial scales is proposed, not limited to MVs and argued to be applicable to other deepsea settings. 
Fig. 1

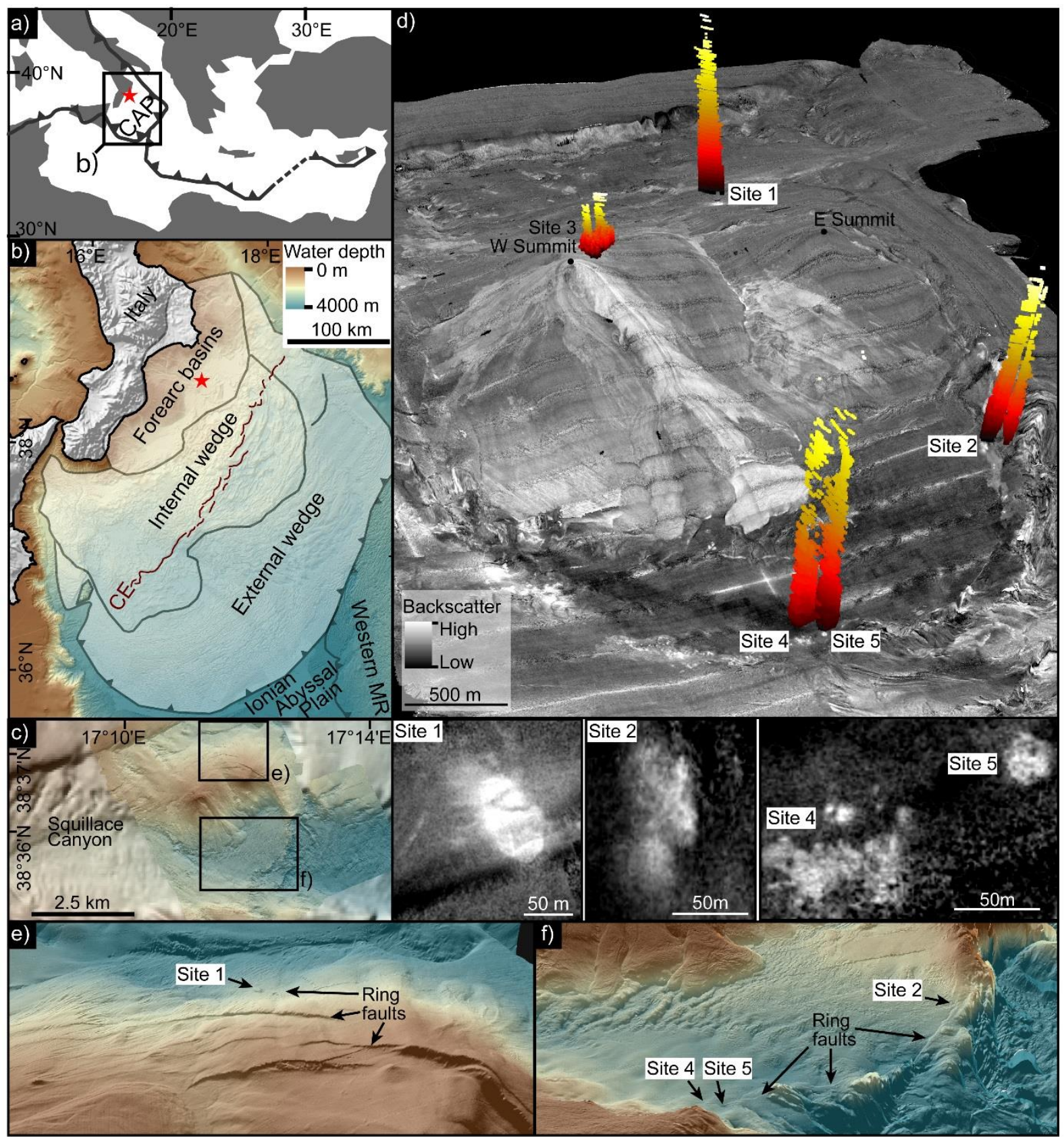

Figure 1. a: Location of the Calabrian Accretionary Prism (CAP) within the central to eastern Mediterranean subduction system (teethed lines indicate plate boundaries); b: Location of Venere MV (red star) on the inner CAP relative to its main morpho-structural zones (CE = Calabrian Escarpment; see text for references); bathymetry from EMODnet, www.emodnet.eu/bathymetry); c: AUV-borne bathymetry draped on ship-borne bathymetry showing Venere MV; d: Perspective view on AUV-borne (v.e. ca. 8x) with locations of peripheral seeps (Sites 1, 2, 4, 5) investigated in this study and shown in map view below; Site 3 slightly below the western summit of Venere MV was not investigated here; 
hydroacoustic anomalies in the water column are shown as flares in red-yellow colors; $e+f$ : Perspective views on AUV-borne bathymetry (see c) for extent) at locations of peripheral seeps (e: Site 1 and f: Sites 2, 4, 5) and ring faults.

\section{Background}

\subsection{Calabrian accretionary prism (CAP)}

The CAP lies above the Eurasian-African subduction zone (Fig. 1a) and has developed during the SE rollback of a NW-dipping Tethyan lithospheric slab that has undergone fragmentation and narrowing to its present width of $300 \mathrm{~km}$ (Malinverno and Ryan 1986; Gueguen et al. 1998). The CAP consists of an accreted thrust-stack of Mesozoic-Cenozoic strata intercalated with pre-Mesozoic metamorphic basement in and near Calabria (Gueguen et al. 1998; Van Dijk et al. 2000; lannace et al. 2007). These units are overlain by forearc basins that contain strata dating back to the Miocene (Roda 1964; Rossi and Sartori 1981; Zecchin et al. 2015). Landward of the Ionian abyssal plain, the CAP can be subdivided into three main morpho-structural domains (Fig. 1b): 1) an external post-Messinian wedge (including Messinian evaporites); 2) an internal pre-Messinian wedge (mainly composed of clastic sediments); and 3) forearc basins both offshore Calabria, and exposed onshore due to km-scale uplift during the late Pleistocene (Rossi and Sartori 1981; Westaway 1993; Minelli and Faccenna 2010; Polonia et al. 2011; Ceramicola et al. 2014; Gutscher et al. 2017). The internal wedge is divided into inner and outer parts by the up to $750 \mathrm{~m}$ high Calabrian Escarpment (Fig. 1b). At least 53 MVs have been identified across the internal CAP and its forearc basins, the majority of which are located landwards of the Calabrian Escarpment (Ceramicola et al. 2014; Loher et al. 2018). Mud volcanism in the CAP is argued to have been triggered by a mid-Pliocene tectonic reorganization (ca. 3.5 Ma ago; (Praeg et al. 2009)), and high acoustic backscatter (12 kHz) from most MVs on the CAP indicate mud breccia extrusion within the last 56 ka (Ceramicola et al. 2014). Mud breccia extrusions are argued to result from the rise of overpressured fluids from deep within the CAP and their interactions with mud-rich sediments and tectonic structures (Praeg et al. 2009; Ceramicola et al. 2014). Evidence of present-day gas seepage in the CAP is so far limited to MVs located in the forearc basins (Ceramicola et al. 2014; Loher et al. 2018).

\subsection{Venere MV}

Previous studies (Loher et al. 2018) have documented recent mud breccia extrusion and gas release at Venere MV (discovered by Ceramicola et al. (2014)) and confirmed these forms of activity by repeated, AUV-based bathymetric mapping (Loher et al. 2018). Venere MV consists of a twin-cone edifice rising $\sim 100 \mathrm{~m}$ from the seafloor in $\sim 1600 \mathrm{~m}$ water depth, 
located in Squillace Canyon (Figs. $1 c+d$ ). Loher et al. (2018) describe the extrusion of mudflows from the summit of the western cone, consisting of exposed mud breccia with gasrich, mousse-like sediment textures. Venere MV is characterized by inward dipping ring faults defining a sub-circular subsidence caldera up to $3 \mathrm{~km}$ in diameter (Figs. 1c-f). Four peripheral fluid seepage sites were identified along these ring faults based on the occurrence of gas flares and the presence of authigenic carbonates and chemosynthesis-based ecosystems at the seafloor (Bohrmann et al. 2015; Loher et al. 2018). Analyses of the gas released at the peripheral seeps point to a thermogenic origin based on the wetness and isotopic composition of methane (Bohrmann et al. 2015; Blumenberg et al. 2017). The ring faults, are argued to provide migration pathways for gas rising along the MV plumbing system. Moreover, the co-existence of mud extrusion and gas release at peripheral seeps as well as subsidence-induced ring faulting, indicates persistently high subsurface pore fluid pressures drive activity at Venere MV (Loher et al. 2018). Temperature measurements in the upper $5 \mathrm{~m}$ of mud breccia being extruded at the western summit show that they are too warm to support gas hydrate formation, whereas lower temperature gradients at the peripheral seeps indicate the gas hydrate stability zone to extends $8-10 \mathrm{~m}$ below the seafloor (Loher et al. in review).

\section{Data and methods}

Cold seep sites at the periphery of Venere MV were examined through the integration of swath echosounder data, seafloor observations, carbonate samples, and photomosaics obtained during RV METEOR cruise M112 (2014) and RV POSEIDON cruise POS499 (2016). Data acquisition, processing, and visualization were carried out according to the following approach, also outlined in Fig. 2. Swath bathymetry and backscatter data were obtained with a Kongsberg EM122 (12 kHz) ship-borne system and an EM2040 (400 kHz) system mounted on autonomous underwater vehicle (AUV) MARUM-SEAL 5000. Swath echosounder data processing was carried out with MB-System software suite (Caress and Chayes 1996) and AUV-borne bathymetry was tied to the ship-borne bathymetry by setting anchor points at prominent morphological features using the navigation adjustment tool (MBnavadjust) and gridded at $1.6 \mathrm{~m}$ lateral resolution and decimeter-scale vertical resolution. Water column data were imported into QPS Fledermaus Midwater Tool and after contrast enhancement, flares were extracted as sd-format files for display together with bathymetric data in the 3-D Fledermaus software. Seafloor observations, sampling, and photographic acquisitions were conducted using the remotely operated vehicle (ROV) MARUM QUEST $4000 \mathrm{~m}$. Photos used to construct photomosaics were obtained from altitudes 1-5 m above seafloor using a Prosilica GT6600C camera vertically mounted on the ROV. A total of 5 
photomosaics (based on 103, 212, 345, 408, and 1314 photos) were compiled with the LAPM tool (Marcon et al. 2013a) and geo-referenced by using the smoothed ultra-short baseline (USBL; IXSEA Posidonia 6k) navigation data of the ROV. Seafloor positioning by USBL has an accuracy better than $10 \mathrm{~m}$, or $0.05-0.2 \%$ of the slant range (Bohrmann et al. 2015). Offsets between AUV-borne bathymetric data and photomosaics have been rectified by manually applying horizontal shifts $(10-50 \mathrm{~m})$ to the final mosaics in Global Mapper $\AA$ software based on obvious seafloor structures. A selected area of one photomosaic at Site 1 was further compiled with the software Agisoft PhotoScan Professional to obtain a 3Dorthographic mosaic.

Fig. 2

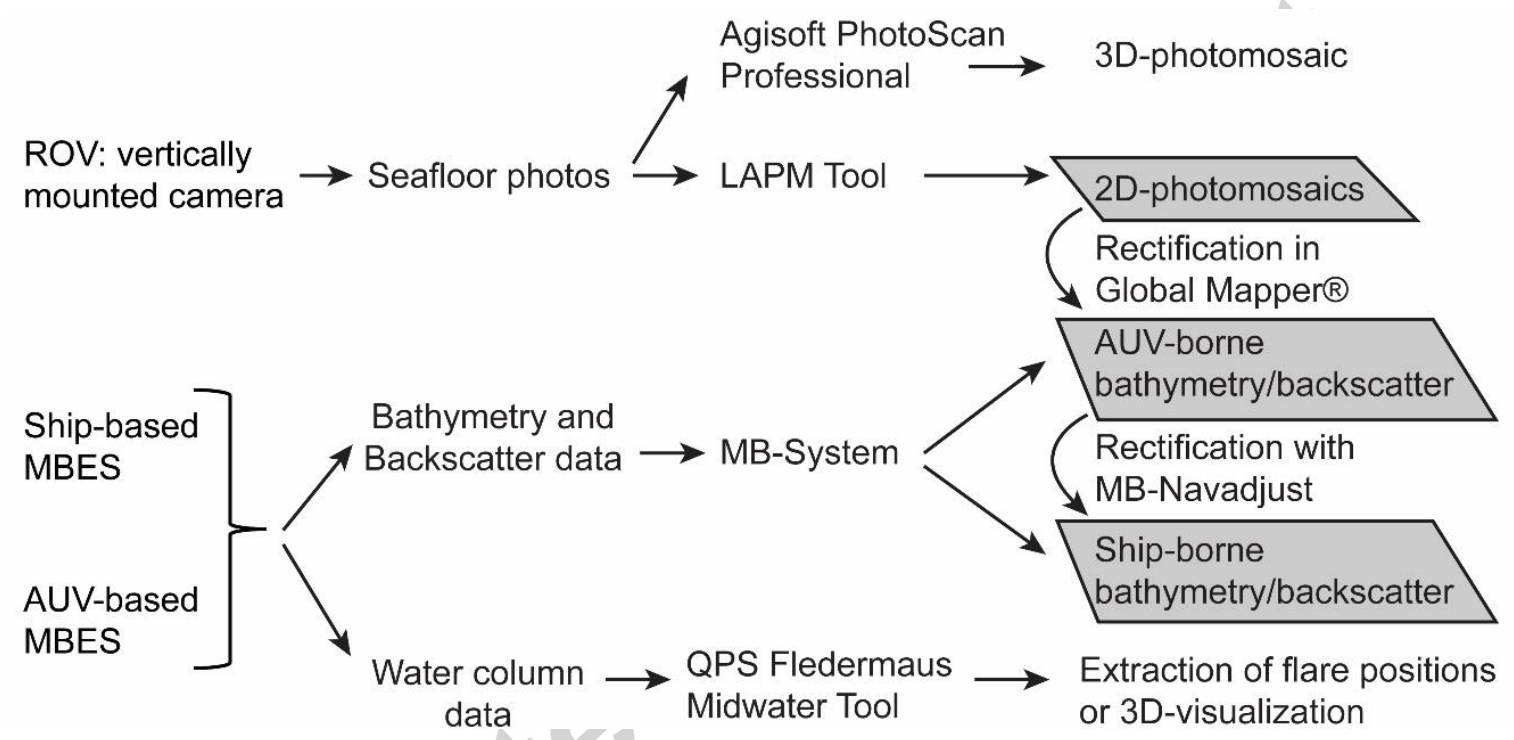

Figure 2. Work flow for the seafloor data acquisition, processing, and visualization carried out in this study. Geo-referenced spatial data (grey shaded layers) were analyzed and displayed via geographic information systems (ArcGIS; Global Mapper ${ }^{\circledR} ;$ QPS Fledermaus). LAPM Tool = Large-Area Photo-Mosaicking Tool (Marcon et al. 2013a); ROV = remotely operated vehicle; $A U V=$ autonomous underwater vehicle; MBES = multibeam echosounder.

A total of six carbonate samples were analyzed in this study, five collected using the ROV at Sites 1, 4, and 5 and one from the top of a gravity core at Site 1 (GeoB19205-2; see Table 1 for coordinates). The carbonate samples were cleaned and dried before being cut into slabs. A sub-sample (ca. 1-2 $\mathrm{cm}^{3}$ ) of each slab was ground to powder $(<20 \mu \mathrm{m})$ in an agate mortar. X-ray diffraction (XRD) analyses on the powder were carried out on a Philips X'Pert Pro MD $\mathrm{X}$-ray diffractometer (PANalytical, Eindhoven, The Netherlands; Cu- $\mathrm{K}_{\alpha}$ tube; $\mathrm{k}=1.541 ; 45 \mathrm{kV}$, $40 \mathrm{~mA}$ ) at the Research Group Crystallography, Department of Geoscience, University of 
Bremen. XRD-patterns were obtained from 3-85 $2 \theta$ using a step size of $0.016^{\circ} 2 \theta$ and a time step of $100 \mathrm{~s}$. Standard deviations for bulk mineral determinations typically range from $+/-1 \%$ for carbonates, $+/-2 \%$ for quartz, and $+/-5-10 \%$ for clays (Vogt et al. 2002). The shift in the $d$-spacing of the (104) reflection was used to calculate the content of magnesium $\left(\mathrm{Mg}^{2+}\right)$ in carbonate minerals following standard equations by Goldsmith et al. (1961). For simplicity, low-magnesium-calcite $\left(<5 \mathrm{~mol}-\% \mathrm{MgCO}_{3}\right)$ is referred to as calcite and high-Mg-calcite ( $>5$ mol- $\% \mathrm{MgCO}_{3}$ ) is referred to as $\mathrm{Mg}$-calcite.

A handheld micro-drill was used to obtain powdered sub-samples for isotopic analyses from each slab. Similar to the procedure reported by Himmler et al. (2015) the carbonate powder was completely reacted to carbon dioxide $\left(\mathrm{CO}_{2}\right.$; by $100 \%$ phosphoric acid at $\left.75^{\circ} \mathrm{C}\right)$. Stable carbon and oxygen isotopes of the released $\mathrm{CO}_{2}$ were analyzed with a "Finnigan MAT 251" mass spectrometer at the Stable Isotope Laboratory at MARUM. Reproducibility of the analyses was checked against repeated measurements of an internal standard (Solnhofen limestone, calibrated with the NBS19 standard) and results of $\delta^{13} \mathrm{C}$ and $\delta^{18} \mathrm{O}$ are reported in per mill (\%) relative to the Vienna-Pee Dee Belemnite standard (V-PDB). The standard deviations are $0.04 \%$ for both $\delta^{13} \mathrm{C}$ and $\delta^{18} \mathrm{O}$. Equilibrium stable oxygen isotopic compositions of the fluids as well as temperatures from which the carbonates may have precipitated were calculated according to experimental fractionation equations (Patterson et al. 1993) following standard approaches for authigenic carbonates as detailed by Bohrmann et al. (1998) and Han et al. (2004). For these calculations the $\delta^{18} \mathrm{O}$ values have been translated to the Vienna-Standard Mean Ocean Water (V-SMOW) scale following Friedman and O'Neil (1977).

\section{Results}

\subsection{High-backscatter morphologies and gas bubble release at peripheral seeps}

Gas release to the water column was recognized from hydroacoustic flares on ship-borne water column data at Sites 1-5 (Fig. 1d), including Site 3 below the summit of Venere MV. The results presented in this study, focus on cold seeps at Sites 1, 2, 4, and 5, all located along the ring-fault system of Venere MV (Figs. 1c-f), and are collectively referred to as peripheral seeps. The peripheral seeps coincide with areas of increased backscatter intensity in AUV-borne data (Fig. 1d) that are up to $130 \mathrm{~m}$ wide and show variability with respect to their morphology and areal extent. Integration with visual observations (Figs. 3-6) shows the patches to correspond to authigenic carbonates and allows visual confirmation and localization of sites of gas bubble release. 
Site 1, on the northern flank of Venere MV (Fig. 1d), is a positive morphological structure ca. $80 \mathrm{~m}$ long and $>50 \mathrm{~m}$ wide, which AUV-borne bathymetry show to rise up to $1.7 \mathrm{~m}$ above surrounding areas of flat seafloor (Fig. 3a). Site 1 consists of a central area of high backscatter surrounded by a diffuse halo of intermediate intensity, from which gas bubble emissions to the water column were visually observed (Fig. 3a+b). The highest backscatter intensities are associated with several superimposed elongate mounds $0.5-1 \mathrm{~m}$ high and ca. $10 \mathrm{~m}$ long. Site 2 lies on the eastern rim of Venere MV (Fig. 1d), at the foot of a ca. $40 \mathrm{~m}$ high scarp of the ring-fault system (Fig. 4a). It coincides with an irregular, ovoid patch of elevated backscatter up to $130 \mathrm{~m}$ long and $50 \mathrm{~m}$ wide (Fig. 4b), of lower overall intensity than that at Site 1. Gas bubble release was documented from a site with moderate backscatter intensity in the central area of the patch. Sites 4 and 5 lie on the southern edge of the caldera about 120 m apart (Fig. 1d). Site 4 consists of an irregular patch of high backscatter up to 80 $\mathrm{m}$ wide and $50 \mathrm{~m}$ in north-south direction, while Site 5 to the NE consists of a circular backscatter patch $30 \mathrm{~m}$ across (Fig. 1d). Gas bubble release occurred from several sites within the elevated backscatter area at Site 4 and from the center of the circular patch at Site 5. 


\section{ACCEPTED MANUSCRIPT}

\section{Fig. 3}
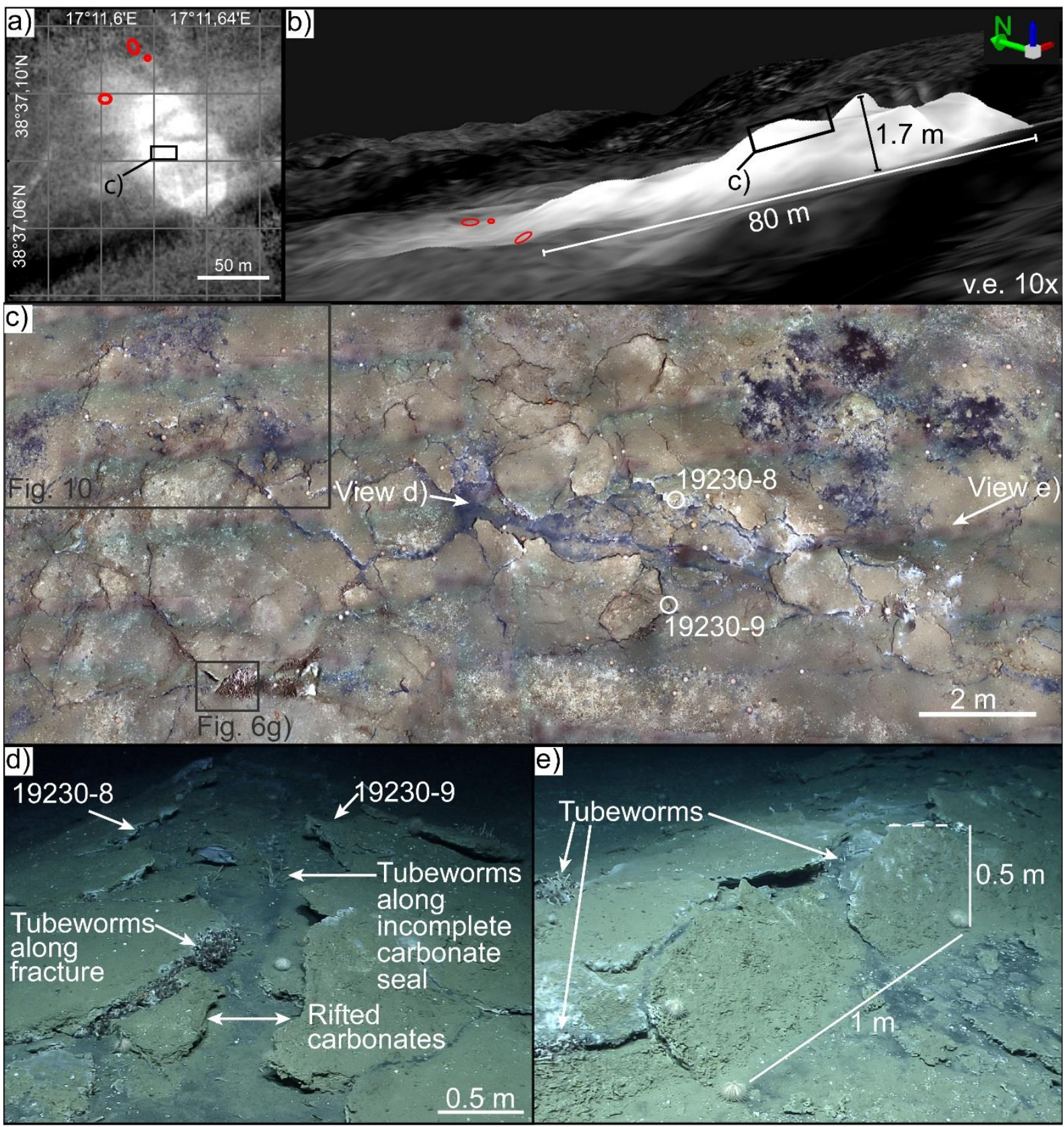

Figure 3. Site 1 (location in Fig. 1); a: Map view of AUV-borne backscatter and visually identified gas bubble emission sites (red circles); b: Perspective view of AUV-borne multibeam bathymetry draped with backscatter (white is high backscatter) and the location of gas bubble emission sites (red circles); c: Photomosaic (see $a+b$ for extent) of ruptured mound, note carbonate slabs with black sediment in between; carbonate sample identifier (GeoB19230-8 and -9) are indicated; d+e: seafloor photos showing updomed carbonate slabs (see c) for orientation). 
Fig. 4
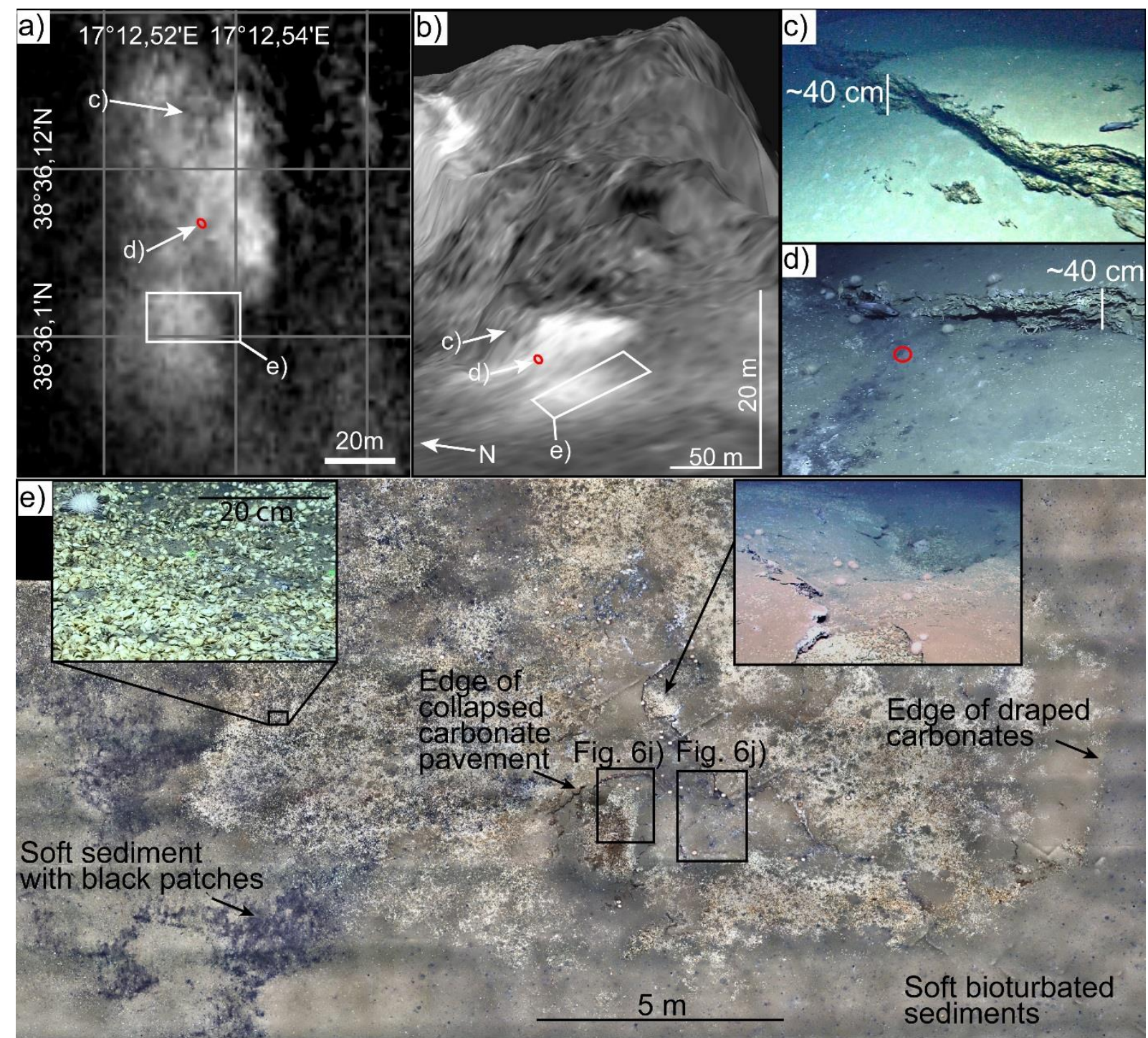

Figure 4. Site 2 (location in Fig. 1); a: Map view of backscatter (white is high backscatter) and visually identified gas bubble emission site (red circle); b: Perspective view of AUV-borne bathymetry draped with backscatter; $c$ : Photo of massive carbonate outcrop in northern part of site 2 (location in b); d: photo of gas bubble emission site (red circle) among outcropping carbonates at Site 2 (location in b); e: Photomosaic (see $a+b$ for extent) of extensive carbonate pavement (note correspondence of right edge of draped carbonate with onset of lower backscatter in b); inset at left shows close-up of seafloor littered with vesicomyid clam shells, inset at right shows seafloor depression lined by carbonates. 


\section{ACCEPTED MANUSCRIPT}

Fig. 5
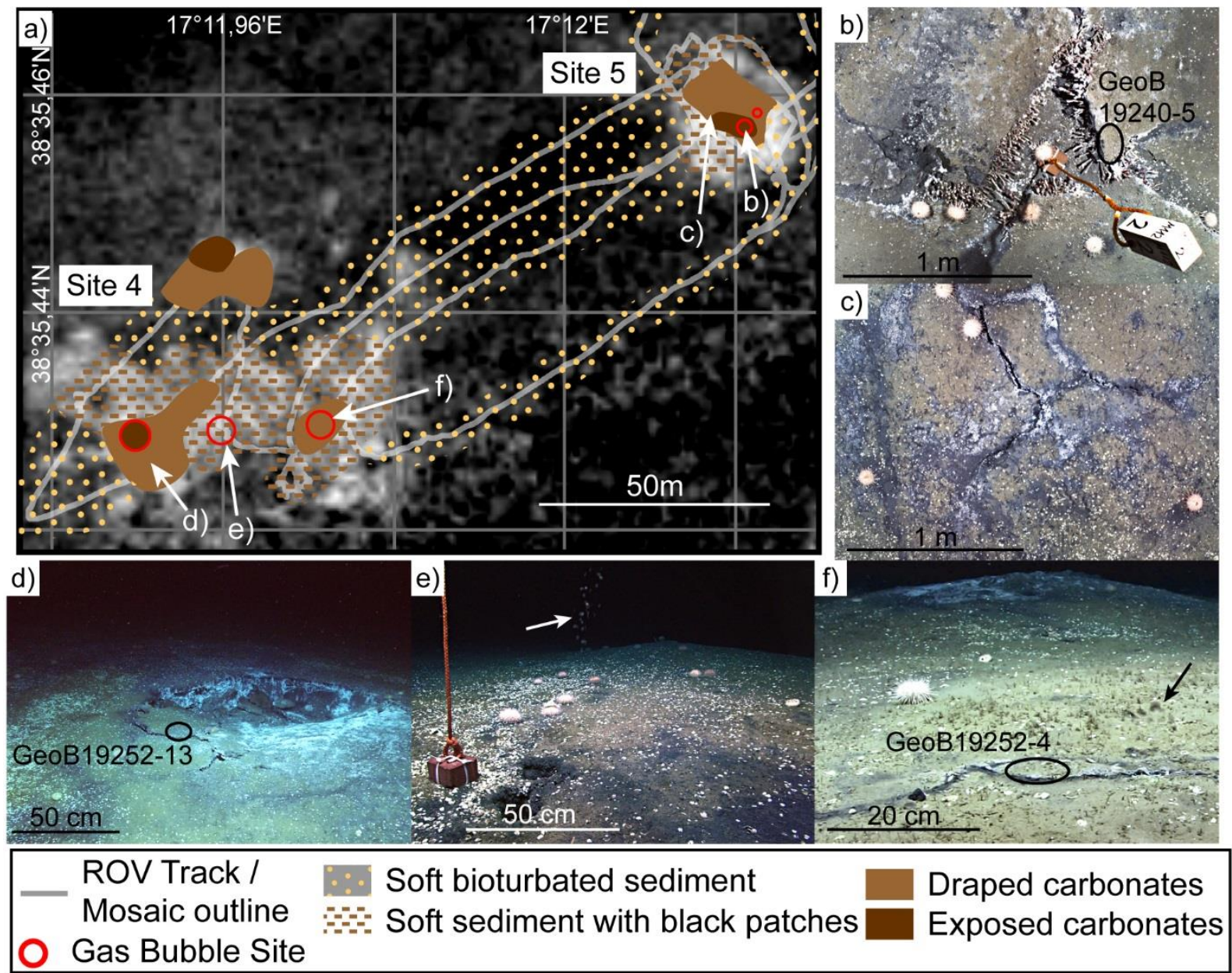

Figure 5. Sites 4 and 5 (location in Fig. 1); a: Map view of AUV-borne backscatter (white is high backscatter) superimposed with seafloor categories mapped along the ROV track and the location of a photomosaic at Site 5; visually identified gas bubble sites; b: Detail of photomosaic at Site 5 showing a ruptured mound releasing gas bubbles (see also supplementary video S4) and tube worms underneath the carbonate slabs; c: Detail of photomosaic at Site 5 showing white microbial mats between carbonate pavements next to the ruptured mound; $d$ : Collapse structure at Site 4; e: Gas bubbles (white arrow) rising from black sediment (note holes from push-core sediment sampling next to red marker) and partially sealed mound in the background; f: Gas bubble release (black arrow) from a fracture in carbonate pavement (black circle marks GeoB-No. of carbonate sample) with partially sealed carbonate mound (note white microbial mats on top). 
Fig. 6
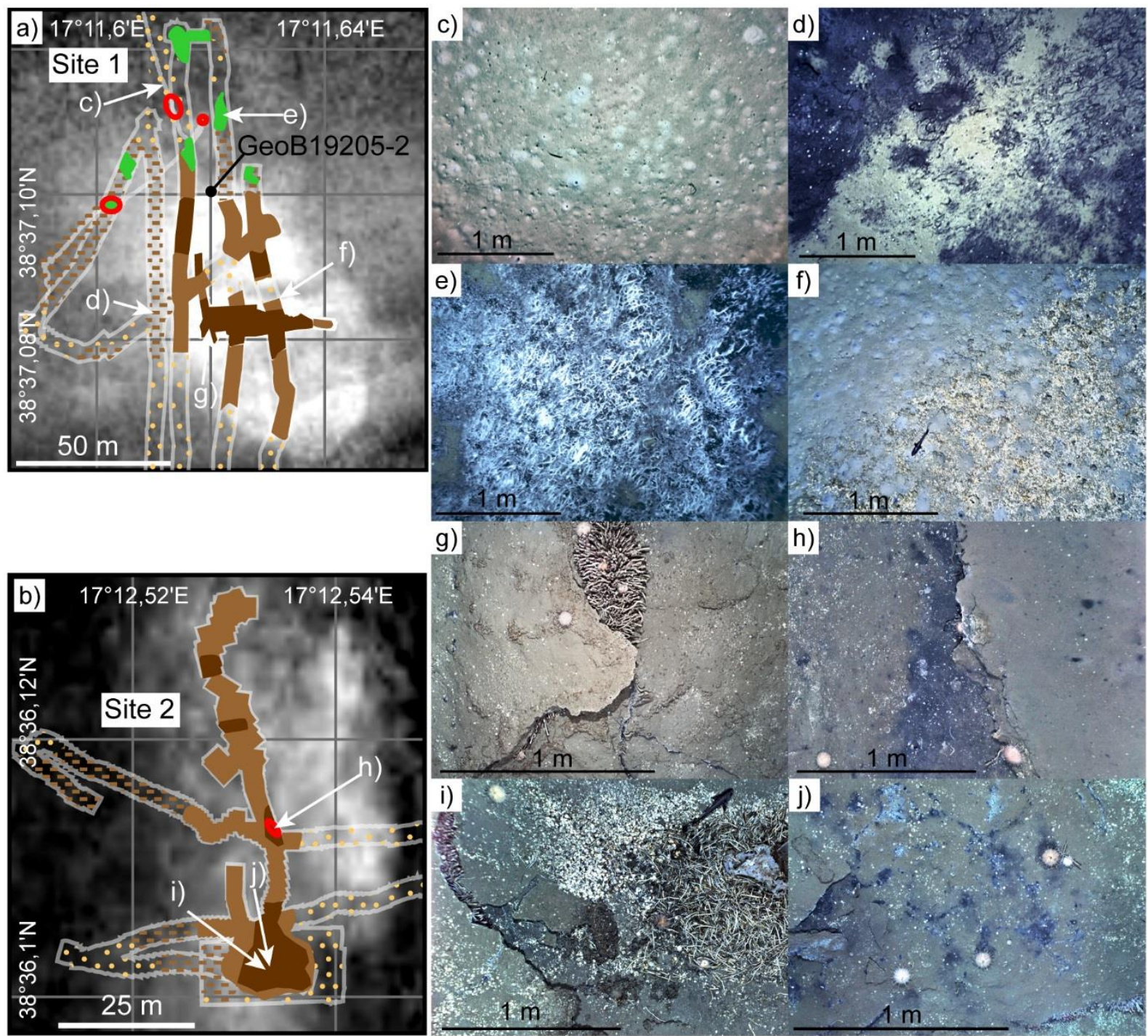

g)

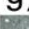

h)

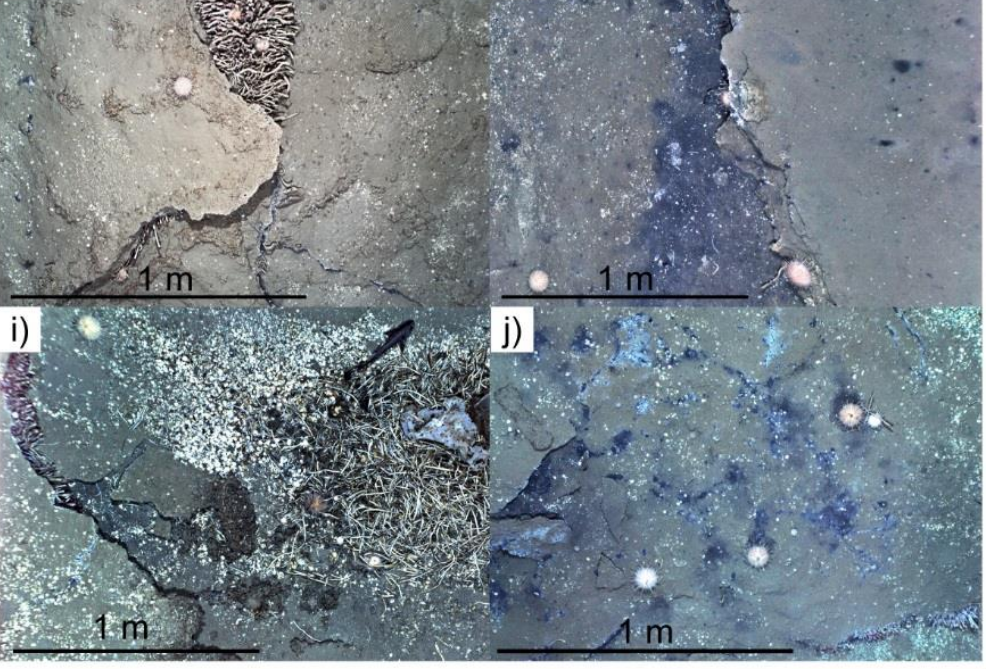

ROV Track /

Soft bioturbated sediment Mosaic outline Soft sediment with black patches Soft sediment with white patches

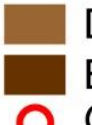

Draped carbonates Exposed carbonates Gas Bubble Site

Figure 6. Sites 1 and 2 (location in Fig. 1); $a+b$ : Map views of AUV-borne backscatter (white is high backscatter) superimposed with seafloor categories mapped along the ROV tracks and the locations of photomosaics; gas bubble sites are visually identified. At Site 1 a carbonate sample obtained by gravity corer is shown by its GeoB number; $c-j)$ Details from the photomosaics (locations shown as white arrows in $a+b$; for $i+j$ see also Fig. 4) illustrating the different seafloor categories that have been mapped; see text for detailed explanations. 
Fig. 7
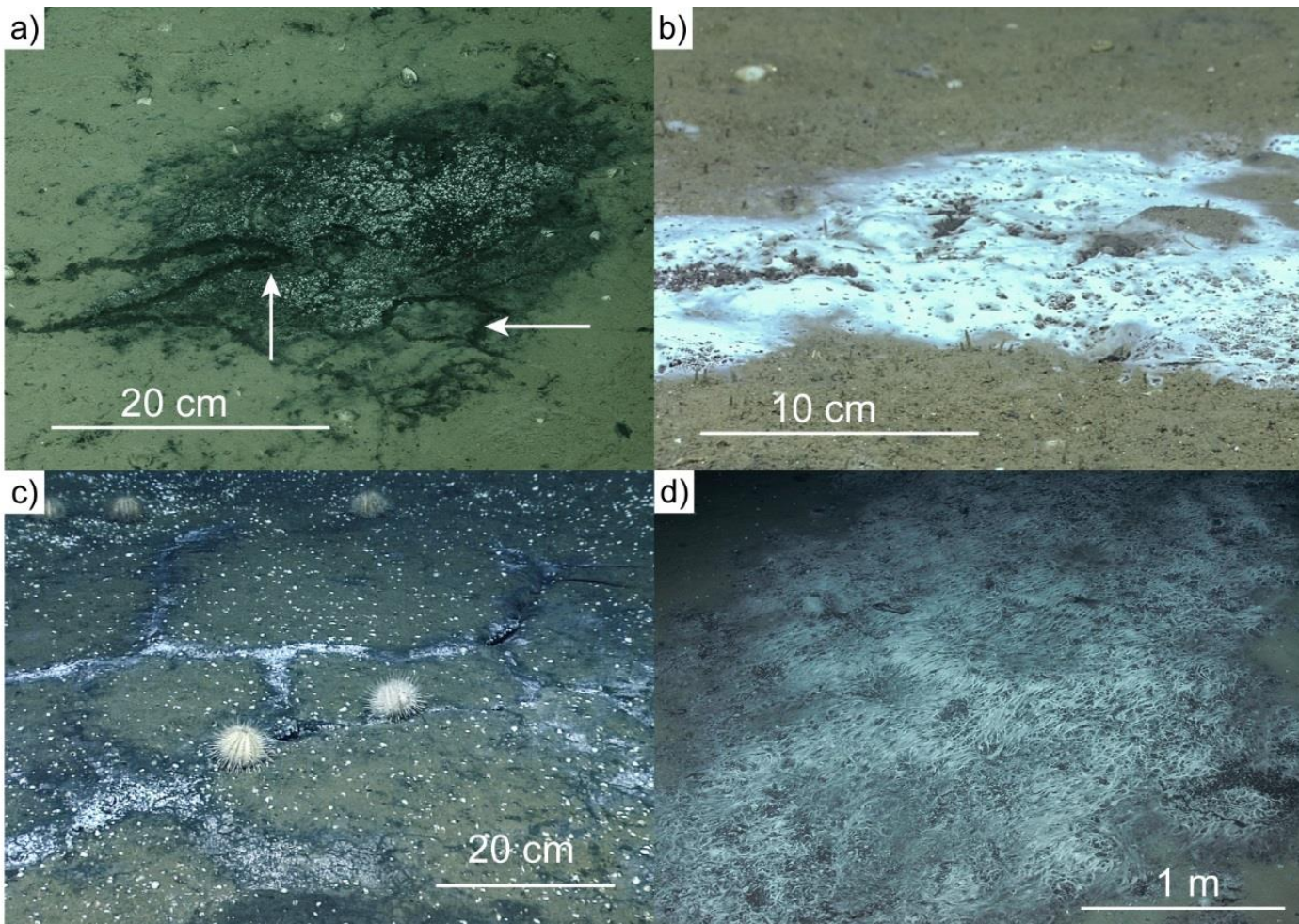

d)

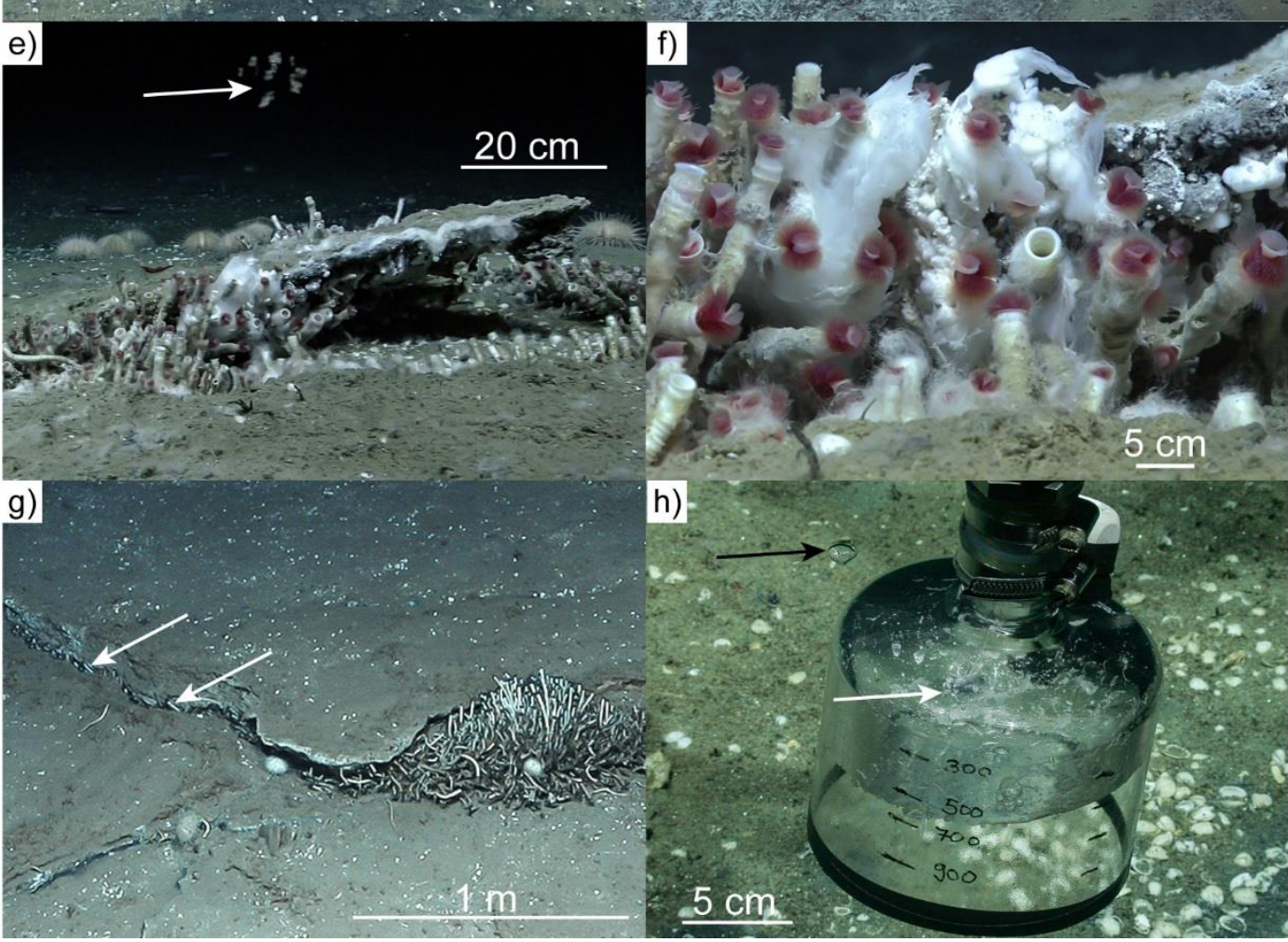

Figure 7. a: Patch of black sediment with few white microbial mats, note crawl paths (white arrows) of presumably alive vesicomyid clams, location at $\mathrm{N}$ rim of high backscatter at Site 1; b: Small patch of intense, white microbial mat on soft sediment (location near Site 5); c: Carbonates draped by a thin veneer of hemipelagic sediment with black sediment populated 
by white microbial mats along fractures (location near Site 5); d: Large patch of filamentous, white microbial mats on soft sediment (location of Fig. 6e); e: Gas bubble release at Site 5 (location as Fig. 5b and supplementary video S4) with white microbial mats and tube-worm colonies rooting below carbonate outcrop; f: Close-up of vestimentiferan tube worms in e); $g$ : Large tube-worm colony (location as Fig. $6 \mathrm{~g}$ ) along fractures (white arrows) rooting below thick carbonate slabs; h: Gas (note bubble at black arrow) collected inside in a gas bubble sampler forms gas hydrate around the rim of the gas bubbles (white arrow; location at Site 1).

\subsection{Visual observations of peripheral seeps}

Visual documentation and photomosaics of the four seep sites allow for the distinction of five categories of seafloor morphologies (Figs. 5+6): 1) soft bioturbated hemipelagic sediments (Fig. 6c); 2) soft hemipelagic sediments with patches ( $\mathrm{cm}$ to $\mathrm{m}$ in diameter) of black sediment and white filamentous microbial mats ( $<50 \%$ coverage; Figs. $6 \mathrm{~d} ; 7 \mathrm{a}+\mathrm{b}) ; 3$ ) soft hemipelagic sediments populated by dense (>50 \% coverage) filamentous white microbial mats (Figs. 6e and $7 \mathrm{~d}$ ); 4) hard carbonates overlain by a dusting of hemipelagic sediments and/or large numbers of shells and tube worm (tube) remains (Figs. $4 c+d, 5 c, 6 f+h-j, 7 c$ ); 5) carbonates exposed at seafloor including chemosynthesis-based organisms in fractures (Figs. 5b, $6 \mathrm{~g}$, $7 e-g)$. Categories 4 and 5 both included cracks or ruptures in the carbonates, often filled by black sediments, which made it possible to identify pavements even below a thin (few $\mathrm{mm}$ to $\mathrm{cm}$ ) cover of hemipelagic sediments (Figs. 5c, 6j, 7c). Carbonate pavements exposed or thinly mantled by sediments (category 4 and 5) cover areas of up to several tens of square meters (Figs. 5a, 6a+b). An increased degree of bioturbation was consistently observed at transitions from hemipelagic sediments (category 1) or from areas with black patches (category 2) to areas with buried carbonates (category 4; Fig. 6f). Shell detritus (Fig. 4e), predominantly of vesicomyid clams, litter the seafloor in areas of black patches and buried carbonates. Vesicomyid clams, presumed to be alive, were observed along crawl paths within black patches (Fig. 7a). In addition, sites of gas bubble release were documented at all of the peripheral seeps (Figs. $5 a, 6 a+b)$.

At Site 1 gas bubbles were observed to emanate from three emission sites (Fig. 6a). They rise from $\mathrm{mm}$ - to $\mathrm{cm}$-sized holes in the black sediment patches or, where these were covered by dense aggregations of filamentous mats, in their immediate vicinity (centimeters to decimeters away). Intense bubble streams were observed to evacuate sediment grains and form $\mathrm{cm}$-scale mounds of black sediment around the emission holes. Gas bubbles trapped inside a bubble sampler spontaneously formed gas hydrate surrounding the gas bubbles (Fig. 
7h) and upward-floating flakes of white material, assumed to be gas hydrate, were repeatedly observed during or after push-core sampling (see supplement videos S1 and S2). Gas bubble streams or pulses were also observed to rise from holes in an area of bioturbated hemipelagic sediment ca. $10 \mathrm{~m}$ across that contained no other seepage features. All three gas ebullition sites were located at the northeastern edge of the high-backscatter area (Figs. $3 b+6 a)$, which corresponds to a positive morphological structure formed by carbonate crusts. Photomosaics at Site 1 (Fig. 3c) reveal a ca. 5 m wide, $20 \mathrm{~m}$ long and up to $1 \mathrm{~m}$ high mounded ridge, composed of upward convex carbonate slabs (Figs. $3 d+e)$. At the apex of the structure the carbonates appear ruptured and rifted apart (Fig. 3d), with black sediments within the ruptures and fractures along the flanks of the structure. No gas bubble emissions were observed in this area. White microbial mats were recognized along the edges of the ruptures. Bush-like colonies of tube worms (vestimentiferan tube worms possibly of the genus Lamellibrachia anaximandri) were observed in cracks between carbonate slabs and are inferred to root below the slabs (Figs. $3 \mathrm{~d}+7 \mathrm{~g}$ ). Vesicomyid clams and their shell remains are observed in the soft substrate (black sediment) between the carbonates and around the ridge structure.

Site 2 is characterized by authigenic carbonate pavements, clam shells, patches of white filamentous mats, and several clusters of tube worms surrounded by hemipelagic sediments containing black patches (Figs. $4 e+6 b$ ). A gas bubble stream was observed to rise from a patch of black sediments a few dm west of an outcrop of carbonates (Figs. $4 c+d$ ). The top of the carbonates was draped by hemipelagic sediments and black patches (a few $\mathrm{cm}$ in diameter; Fig. 6h). An area showing $>150 \mathrm{~m}^{2}$ of exposed carbonate pavement extends south of the outcrop (Fig. 6b). In a central area of this pavement, $\mathrm{cm}$ to $\mathrm{dm}$-thick carbonate plates formed an irregular crater-like seafloor depression of $>5 \mathrm{~m}$ extent and ca. $1 \mathrm{~m}$ depth (Fig. $4 \mathrm{e}$ ). Along the ruptures between the plates, filamentous white microbial mats and alive tube worms were observed (Figs. 6h-j). The floor of the crater was covered by shells and empty tube-worm tubes (Figs. 4e+6i). In this southern area, the photomosaic in Fig. 4e shows a close relationship between what is proposed to be the edge of carbonates buried below hemipelagic sediments and the edge of the high-backscatter patch (Fig. 6b).

Site 4 includes two mounds $1.5-2.5 \mathrm{~m}$ in diameter and ca. $0.5 \mathrm{~m}$ high (Figs. $5 \mathrm{e}+\mathrm{f}$ ). The mounds were partly covered by dense accumulations of loose carbonate pieces (few $\mathrm{cm}$ in diameter), hemipelagic sediments, and white filamentous mats associated with black sediments. One of the mounds was mechanically ruptured by inserting a temperature lance, causing the release of gas bubble bursts and the occurrence of schlieren (a term used to describe flow disturbances by inhomogeneous transparent media), indicating the presence of 
pressurized fluid in the subsurface (see supplementary video S3). Cracks in the carbonate pavement at the edge of the mounds hosted clusters of small vestimentiferan tube worms and few microbial mats, and were the emissions sites of weak gas bubble streams at two locations (Fig. 5a). In addition, a crater-like seafloor depression was found (Fig. 5d), similar in size to that observed at Site 2. It consisted of slabs of broken carbonate up to $\mathrm{dm}$ thick, which appeared to have collapsed from a formerly continuous seafloor pavement. Pulses of gas bubbles were observed to be recurrently released from a site among the carbonate pieces, while white filamentous mats covered the edges of the crater and carbonate slabs. No living tube worms or empty tubes were observed within this crater. Around Site 4, the transition from carbonates to soft sediments with black patches (seafloor category 2) correlates with the edge of elevated acoustic backscatter (Fig. 5a).

At Site 5 gas bubble pulses were observed from a circular mound ca. $2 \mathrm{~m}$ wide and $0.5 \mathrm{~m}$ high with ruptured carbonate slabs at its apex (Fig. 7e). The pulsating release of gas bubbles was seen to relate to the presence of a carbonate slab, which formed a ledge that temporarily trapped rising gas bubbles (see supplementary video S4). White filamentous mats covered the ledge and a bush-like colony of tube worms appeared to root underneath it. The carbonate pavement at the foot of the mound was densely covered by shell remains, forming a ring around the mound. A few meters towards the east, the seafloor gave way to carbonates buried by smooth hemipelagic sediments. Southwest of the gas bubble site, the exposed or slightly buried carbonate pavements (categories 4 and 5) gave way to soft sediments with black patches (category 2 ) and finally to soft bioturbated sediments (category 1) consistent with a change from high to low acoustic backscatter Fig. 5a).

\subsection{Mineralogy, petrography, and isotopic composition of carbonate samples}

\subsubsection{Samples from Site 1}

Sample GeoB19205-2 was obtained from the top of a gravity core at the edge of the central high backscatter area (Fig. 6a) and samples GeoB19230-8 and GeoB19230-9 were collected by ROV from up-turned carbonate slabs at a mound-like feature (Figs. $3 c+d$ ). In all three samples, carbonate is the most abundant mineral fraction, predominantly in the form of aragonite (53-60 wt.-\%) with lesser amounts of non-carbonate minerals including quartz and mica (Table 2). Visually, samples GeoB19205-2 and GeoB19230-9 consist of dark grey microcrystalline cement (estimated 50-70\%), light grey lithified hemipelagic sediment (estimated $50-30 \%$ ) and few cm-sized voids and cemented mud clasts (Fig. 8). Shells of mytilid bivalves are present on the surface of sample GeoB19230-9 (Fig. 8a). Sample GeoB19230-8 consists predominantly (estimated up to 75\%) of brownish semi-lithified hemipelagic sediment and areas of dark grey microcrystalline cement (estimated <25\%; Fig. 
8). Several $1-2 \mathrm{~cm}$ wide pores (possibly the remains of cemented tube-worm tubes) as well as light grey cemented mud clasts are present. There is a high content of bivalve shells imbricated as a horizontal layer at the upper side of the sample. Stable oxygen isotope $\left(\delta^{18} \mathrm{O}\right)$ values of the carbonates and range between 1.5 and $3.1 \%$, and stable carbon isotope $\left(\delta^{13} \mathrm{C}\right)$ values range from -27.1 to $-16.8 \%$ (Table 1 , Fig. 9).

\subsubsection{Samples from Sites 4 and 5}

Three samples were obtained by ROV from sites 4 and 5 (120 m apart). At site 4, sample GeoB19252-4 was collected from a fracture in a carbonate pavement in the vicinity of a sealed mound (Fig. 5f). The most abundant mineral fraction is carbonate (53 wt.-\%, predominantly aragonite at $50 \mathrm{wt} . \%$ ), followed by non-carbonate minerals including quartz, mica, sanidine, and anhydrite (Table 2). Sample GeoB19252-13 from Site 4 was collected at a crater-shaped depression (Fig. 5d). The predominant mineral phase is illite (27 wt.-\%) with relatively high amounts of quartz (20 wt.-\%) and a low carbonate content (17 wt.-\% aragonite). Sample GeoB19240-5 from Site 5 was collected at a ruptured mound (Fig. 5b) and consists mainly of carbonate (37 wt.-\%, predominantly aragonite at 34 wt.-\%) but also contains a large fraction of quartz (32 wt.-\%). Visually, samples GeoB19252-4, GeoB1925213, and GeoB19240-5 are porous and consist mainly of brownish semi-lithified hemipelagic sediments (estimated 60-75\%) and dark grey microcrystalline cement (estimated $25-40 \%$; Fig. 8). Cemented tubes of vestimentiferans as well as bivalve shells including vesicomyid clams (Fig. 8b) could be identified. Samples GeoB19252-4 and GeoB19252-13 show layers of imbricated shells and biogenic remains $1-2 \mathrm{~cm}$ below the sample surface. The $\delta^{18} \mathrm{O}$ values of these samples range from -0.7 to $2.9 \%$, and $\delta^{13} \mathrm{C}$ values from -24.7 to $-11.4 \%$ (Table 1 ; Fig. 9).

Table 1: Sites of analyzed rock samples including GeoB identifier and sampling method (via gravity core or ROV), coordinates (WGS84), water depths, and subsamples. The four right-hand columns give numbered micro-drill samples (see Fig. 8 for exact positions) and corresponding $\delta 13 \mathrm{C}$ and $\delta 180$ values and comments on appearance.

\begin{tabular}{|c|c|c|c|c|c|c|c|c|}
\hline Site & GeoB No. & $\begin{array}{l}\text { Latitude } \\
(\mathrm{N})\end{array}$ & $\begin{array}{l}\text { Longitude } \\
\text { (E) }\end{array}$ & $\begin{array}{c}\text { Water } \\
\text { depth } \\
(\mathrm{m})\end{array}$ & $\begin{array}{l}\text { Micro- } \\
\text { drill No. }\end{array}$ & $\begin{array}{l}\delta^{13} \mathrm{C} \% \\
\mathrm{~V}-\mathrm{PDB}\end{array}$ & $\begin{array}{l}\delta^{18} \mathrm{O} \% \\
\mathrm{~V}-\mathrm{PDB}\end{array}$ & Appearance \\
\hline \multirow{4}{*}{1} & \multirow{4}{*}{$\begin{array}{c}\text { 19205-2D } \\
\text { (Top of } \\
\text { gravity } \\
\text { core) }\end{array}$} & \multirow{4}{*}{$38^{\circ} 37.103$} & \multirow{4}{*}{$17^{\circ} 11.620$} & \multirow{4}{*}{1556} & 30 & -25.28 & 2.21 & microcrystalline cement (dark grey) \\
\hline & & & & & 31 & -21.16 & 1.47 & microcrystalline cement (dark grey) \\
\hline & & & & & 32 & -25.08 & 2.03 & microcrystalline cement (dark grey) \\
\hline & & & & & 33 & -16.83 & 1.70 & $\begin{array}{l}\text { semi-lithified sediment or mud clast } \\
\text { (light grey-brown) }\end{array}$ \\
\hline \multirow{2}{*}{1} & \multirow{2}{*}{$\begin{array}{l}19230-8 \\
\text { (ROV) }\end{array}$} & \multirow{2}{*}{$38^{\circ} 37.081$} & \multirow{2}{*}{$17^{\circ} 11.629$} & \multirow{2}{*}{1564} & 14 & -20.71 & 2.84 & fibrous cement (white) \\
\hline & & & & & 15 & -26.73 & 2.27 & microcrystalline cement (dark grey) \\
\hline
\end{tabular}




\begin{tabular}{|c|c|c|c|c|c|c|c|c|}
\hline & \multirow{9}{*}{$\begin{array}{l}\text { 19230-9B } \\
\text { (ROV) }\end{array}$} & \multirow{9}{*}{$38^{\circ} 37.082$} & \multirow{9}{*}{$17^{\circ} 11.629$} & \multirow{9}{*}{1564} & 16 & -24.17 & 2.21 & microcrystalline cement (dark grey) \\
\hline \multirow{5}{*}{1} & & & & & 17 & -23.64 & 2.59 & microcrystalline cement (dark grey) \\
\hline & & & & & 18 & -21.66 & 2.49 & fibrous cement (white) \\
\hline & & & & & 19 & -21.99 & 2.44 & microcrystalline cement (dark grey) \\
\hline & & & & & 20 & -23.40 & 2.06 & microcrystalline cement (dark grey) \\
\hline & & & & & 21 & -27.08 & 3.13 & fibrous cement (white) \\
\hline & & & & & 22 & -24.90 & 2.36 & microcrystalline cement (dark grey) \\
\hline & & & & & 23 & -23.97 & 2.44 & microcrystalline cement (dark grey) \\
\hline & & & & & 24 & -25.81 & 2.35 & $\begin{array}{l}\text { semi-lithified sediment or mud clast } \\
\text { (light grey-brown) }\end{array}$ \\
\hline \multirow{4}{*}{4} & \multirow{4}{*}{$\begin{array}{l}\text { 19252-4 } \\
\text { (ROV) }\end{array}$} & \multirow{4}{*}{$38^{\circ} 35.428$} & \multirow{4}{*}{$17^{\circ} 11.971$} & \multirow{4}{*}{1606} & 34 & -21.09 & 2.01 & microcrystalline cement (dark grey) \\
\hline & & & & & 35 & -13.59 & 2.66 & microcrystalline cement (dark grey) \\
\hline & & & & & 36 & -23.68 & 1.78 & microcrystalline cement (dark grey) \\
\hline & & & & & 37 & -11.36 & -0.67 & $\begin{array}{l}\text { semi-lithified sediment or mud clast } \\
\text { (light grey-brown) }\end{array}$ \\
\hline \multirow{6}{*}{4} & \multirow{6}{*}{$\begin{array}{l}\text { 19252-13B } \\
\text { (ROV) }\end{array}$} & \multirow{6}{*}{$38^{\circ} 35.428$} & \multirow{6}{*}{$17^{\circ} 11.950$} & \multirow{6}{*}{1606} & 2 & -24.70 & 2.91 & fibrous cement (white) \\
\hline & & & & & 3 & -16.14 & 2.51 & fibrous cement (white) \\
\hline & & & & & 4 & -19.98 & 2.44 & fibrous cement (white) \\
\hline & & & & & 5 & -19.17 & 2.45 & microcrystalline cement (dark grey) \\
\hline & & & & & 6 & -21.37 & 2.20 & microcrystalline cement (dark grey) \\
\hline & & & & & 7 & -12.65 & 0.82 & $\begin{array}{l}\text { semi-lithified sediment or mud clast } \\
\text { (light grey-brown) }\end{array}$ \\
\hline \multirow{6}{*}{5} & \multirow{6}{*}{$\begin{array}{l}\text { 19240-5A } \\
\text { (ROV) }\end{array}$} & \multirow{6}{*}{$38^{\circ} 35.457$} & \multirow{6}{*}{$17^{\circ} 12.021$} & \multirow{6}{*}{1607} & 8 & -24.09 & 2.53 & fibrous cement (white) \\
\hline & & & & & 9 & -22.12 & 1.90 & microcrystalline cement (dark grey) \\
\hline & & & & & 10 & -23.18 & 2.31 & microcrystalline cement (dark grey) \\
\hline & & & & & 11 & -20.17 & 1.73 & microcrystalline cement (dark grey) \\
\hline & & & & & 12 & -21.31 & 1.84 & microcrystalline cement (dark grey) \\
\hline & & & & & & -17.14 & 0.69 & $\begin{array}{l}\text { semi-lithified sediment or mud clast } \\
\text { (light grey-brown) }\end{array}$ \\
\hline
\end{tabular}

Table 2: Bulk-rock mineralogy from XRD analyses of rock samples.

\begin{tabular}{cccccccccc}
\hline & & Aragonite & \multicolumn{2}{c}{$\begin{array}{c}\text { Calcite } \\
\text { mol- } \\
\%\end{array}$} & $\begin{array}{c}\text { Mg-calcite } \\
\text { mol- } \\
\%\end{array}$ & Quartz & Illite & Others \\
Site & GeoB-No. & wt-\% & $\begin{array}{c}\text { wt- } \\
\%\end{array}$ & Mg & wt- & wt-\% & $\%$ & wt-\% \\
\hline 1 & $19205-2$ & 53 & 4 & 0 & 1 & 15 & 20 & 0 & 22 \\
1 & $19230-8$ & 60 & 4 & 0 & 1 & 13 & 14 & 0 & 21 \\
1 & $19230-9$ & 53 & 6 & 0 & 1 & 13 & 27 & 0 & 13 \\
4 & $19252-4$ & 50 & 2 & 3 & 1 & 17 & 15 & 0 & 32 \\
4 & $19252-13$ & 17 & 6 & 2 & 2 & 17 & 20 & 27 & 28 \\
5 & $19240-5$ & 34 & 2 & 1 & 1 & 15 & 32 & 0 & 31 \\
\hline
\end{tabular}

Table 3: $\delta^{18} \mathrm{O}$ values averaged per sample from Table 1 and translated to \%o vs. VSMOW following Friedman and O'Neil (1977)); calculated equilibrium temperatures ( $\mathrm{T}$; following Patterson et al. (1993)) and the difference from present-day bottom water $\mathrm{T}$; calculated equilibrium $\delta^{18} \mathrm{O}$ values for aragonite precipitation (following Patterson et al. (1993)), and the difference from presentday bottom water $\delta^{18} \mathrm{O}$. 


\section{ACCEPTED MANUSCRIPT}

\begin{tabular}{|c|c|c|c|c|c|c|c|}
\hline Site & $\begin{array}{c}\text { GeoB- } \\
\text { No. }\end{array}$ & $\begin{array}{c}\delta^{18} \mathrm{O} \\
\text { values } \\
\text { averaged } \\
\text { per sample } \\
(\% \circ \mathrm{V}-\mathrm{PDB})\end{array}$ & $\begin{array}{c}\delta^{18} \mathrm{O} \\
\text { values } \\
\text { averaged } \\
\text { per sample } \\
(\% \circ \mathrm{V}- \\
\text { SMOW) } \\
\end{array}$ & $\begin{array}{c}\text { Calculated equilibrium } \\
\mathrm{T}\left({ }^{\circ} \mathrm{C}\right) \text { for aragonite } \\
\text { precipitation from a } \\
\text { fluid with } \delta^{18} \mathrm{O}=1.5 \% \\
\mathrm{~V}-\mathrm{SMOW}\end{array}$ & $\begin{array}{l}\text { T-difference } \\
\left({ }^{\circ} \mathrm{C}\right) \text { to } \\
\text { present-day } \\
\text { bottom water } \\
\left(\mathrm{T}=13.8^{\circ} \mathrm{C}\right)\end{array}$ & $\begin{array}{c}\text { Calculated } \\
\text { equilibrium } \delta^{18} \mathrm{O} \\
(\% \circ \mathrm{VSMOW}) \text { of } \\
\text { fluid precipitating } \\
\text { aragonite at } \\
\mathrm{T}=13.8^{\circ} \mathrm{C}\end{array}$ & $\begin{array}{c}\text { Difference in } \delta^{18} \mathrm{O}(\% \circ \\
\text { VSMOW) of fluid to } \\
\text { present-day bottom } \\
\text { water } \\
\left(\delta^{18} \mathrm{O}=1.5 \% \mathrm{~V}-\right. \\
\mathrm{SMOW})\end{array}$ \\
\hline 1 & $19205-2$ & 1.9 & 32.8 & 15.8 & 2.0 & 1.1 & -0.4 \\
\hline 1 & $19230-8$ & 2.5 & 33.4 & 13.0 & -0.8 & 1.7 & 0.2 \\
\hline 1 & $19230-9$ & 2.5 & 33.4 & 13.0 & -0.8 & 1.7 & 0.2 \\
\hline 4 & $19252-4$ & 1.4 & 32.3 & 17.6 & 3.8 & 0.6 & -0.9 \\
\hline 4 & $\begin{array}{c}19252- \\
13\end{array}$ & 2.2 & 33.1 & 14.1 & 0.3 & 1.4 & -0.1 \\
\hline 5 & $19240-5$ & 1.8 & 32.8 & 15.9 & 2.1 & 1.0 & -0.5 \\
\hline
\end{tabular}




\section{ACCEPTED MANUSCRIPT}

Fig. 8

\section{Samples from Site 1}
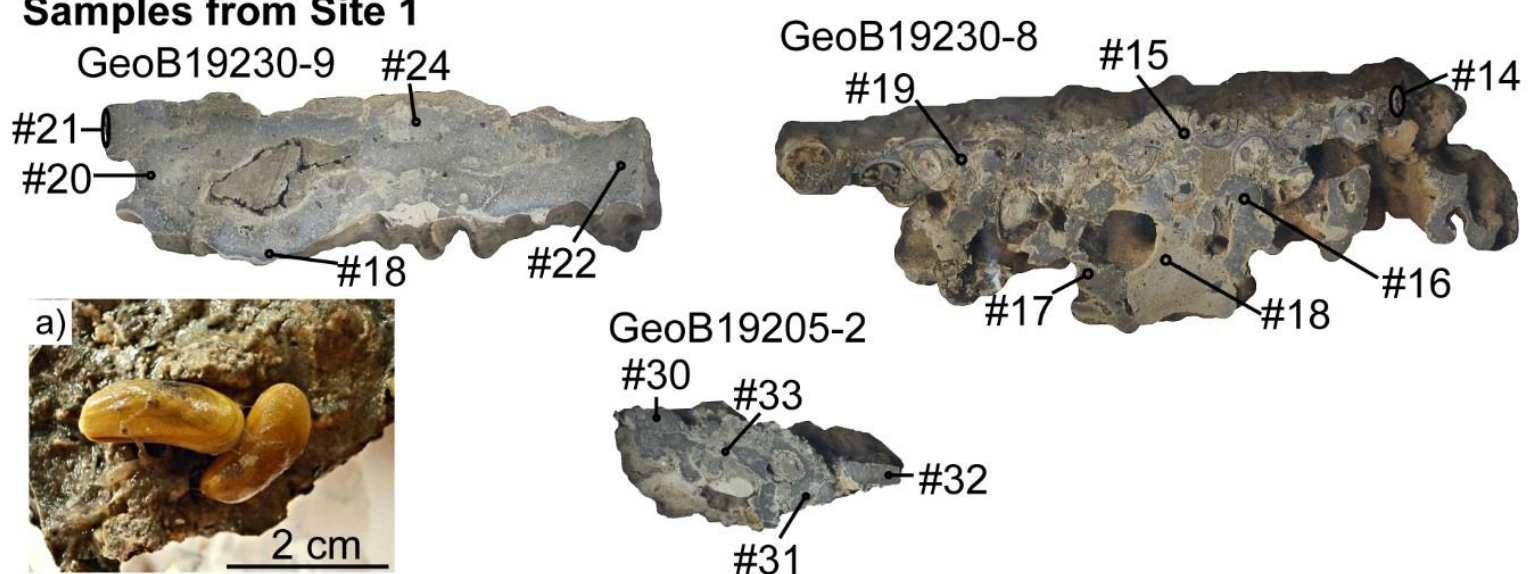

\section{Samples from Site 4}
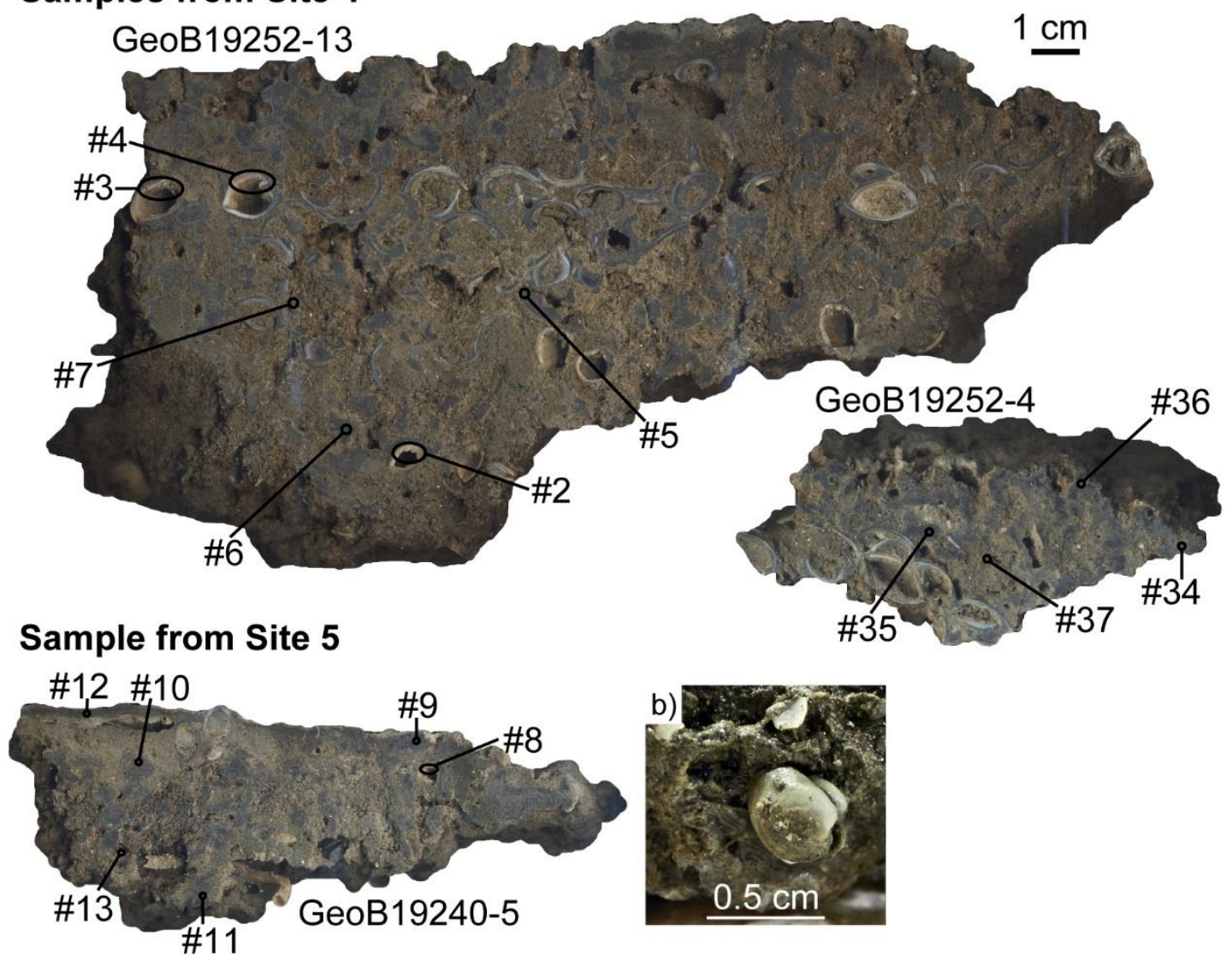

Figure 8: Photographs of samples of carbonates obtained from Sites 1, 2, 4 and 5 (each with GeoB identifier), together with locations and numbers of sub-samples (\#; see Table 1) obtained using a micro-drill. Inset a: photograph of mytilid (possibly Idas modiolaeformis) identified on outside of sample GeoB19230-9. Inset b: photograph of vesicomyid clam (possibly Isorropodon) identified on the outside of sample GeoB19240-5. 
Fig. 9

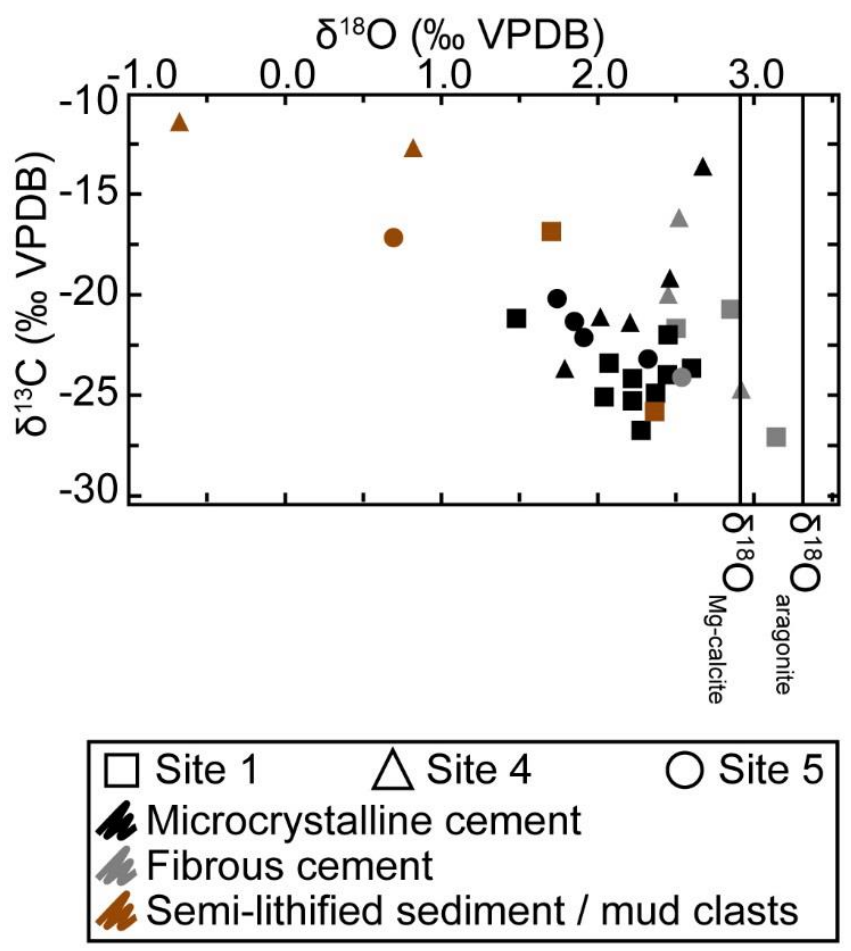

Figure 9: Plot of stable carbon vs. oxygen isotopic compositions of carbonate samples from Sites 1, 4 and 5, color-coded according to the macroscopic appearance of the carbonate phase; vertical lines represent the theoretical $\delta^{18} \mathrm{O}$ value of calcium carbonates (aragonite and $\mathrm{Mg}$-calcite with $12 \% \mathrm{MgCO}_{3}$ content) calculated on the assumption of precipitation in isotopic equilibrium with present-day Mediterranean bottom water (see text for references).

\section{Discussion}

The results presented above provide information on a broad range of possible seafloor features that have developed in response to fluid seepage at four sites peripheral to Venere MV. In the following, the observations and datasets of this study are first placed in the context of the spatial scales of cold seep morphologies. Then the potential fluid sources contributing to the precipitation of the authigenic carbonates studied at the peripheral seeps of Venere MV, in relation to the focused flow of methane-rich fluids, and the presence of methane hydrates are discussed. The processes involved in the formation and deformation of carbonate mounds are then considered in terms of gas pressures and gas hydrate dynamics. Based on the observed spatial variation of seepage structures within and between the four studied seepage sites, an evolutionary model is proposed. It is argued to be generally applicable to the development of seep carbonates and associated chemosynthesisbased communities over timescales from decades to millennia (Fig. 11). 


\subsection{Spatial scales of cold-seep structures}

Venere MV and the associated subsidence caldera is a structure of $3 \mathrm{~km}$ in diameter and $100 \mathrm{~m}$ in height (Loher et al. 2018), but the results presented in this study provide information on the extent and appearance of cold-seep structures at four sites peripheral to Venere MV over spatial scales ranging from centimeters to tens of meters. They reveal areas of reduced sediments indicated by black minerals, likely sulfides that are often present among discontinuous carbonate deposits. The cold-seep structures have exposed (or draped) flat carbonate pavements, collapsed pavement, sealed or ruptured mounds, and chemosynthesis-based fauna. The peripheral seep sites host carbonate deposits of several hundred $\mathrm{m}^{2}$ in extent, which coincide with circular to irregular patches of elevated seafloor backscatter. This is in contrast to other MVs where it has been found that diffusive methane release from mud breccia deposits has led to extensive carbonate deposits covering several thousand $\mathrm{m}^{2}$ (e.g. the Napoli MV on the Mediterranean Ridge; Huguen et al. (2005)). This indicates that seepage occurs at distinct locations along the ring faults of Venere MV. The extents, morphologies, and sediments of the peripheral seeps at Venere MV resemble patches of cold seeps known from sites not related to MVs, such as on the Nile Deep Sea Fan (Römer et al. 2014), in the Black Sea (Naudts et al. 2008) or those found associated to pockmarks (e.g. Hovland (2002)). Typically, authigenic carbonates precipitate as individual cemented nodules up to several $\mathrm{cm}$ in diameter (Aloisi et al. 2000; Gontharet et al. 2007), or form $\mathrm{mm}$ - to $\mathrm{dm}$-thick crusts that extend as seafloor pavements over areas of $10^{0}-10^{2} \mathrm{~m}^{2}$ (Gontharet et al. 2007; Himmler et al. 2011; Römer et al. 2014). Carbonates may form mounds of varying height from decimeters to meters (Gontharet et al. 2007; Römer et al. 2014; Himmler et al. 2015) to several tens of meters (Buerk et al. 2010). Carbonates may also grow as irregular structures vertically upward into the water column (up to several tens of meters) as chemoherms (Teichert et al. 2005) but this was not observed at Venere MV.

Whereas cold-seep structures at meter scale are readily revealed in AUV-borne bathymetry (Fig. 3b), this study also illustrates decimeter-scale structures across the most active seepage areas (Fig. 6+7). For example, the largest positive morphology investigated is at Site $1,>80 \mathrm{~m}$ long and up to $1.7 \mathrm{~m}$ high (Fig. 3b). This structure includes a ca. $50 \mathrm{~cm}$ high mounded ridge at its center (Fig. 3e). The flank of this ridge hosts collapsed and ruptured carbonate slabs with vertical offsets on the order of 7 and $10 \mathrm{~cm}$, respectively, revealed in a 3D-photomosaic (Fig. 10; see supplement S5 for movable turntable 3D-version). The 3Dphotomosaic gives a comprehensive view of cold-seep structures, bridging scales of several tens of meters to decimeters, which is often lacking in the presently available literature. 


\section{ACCEPTED MANUSCRIPT}

Fig. 10

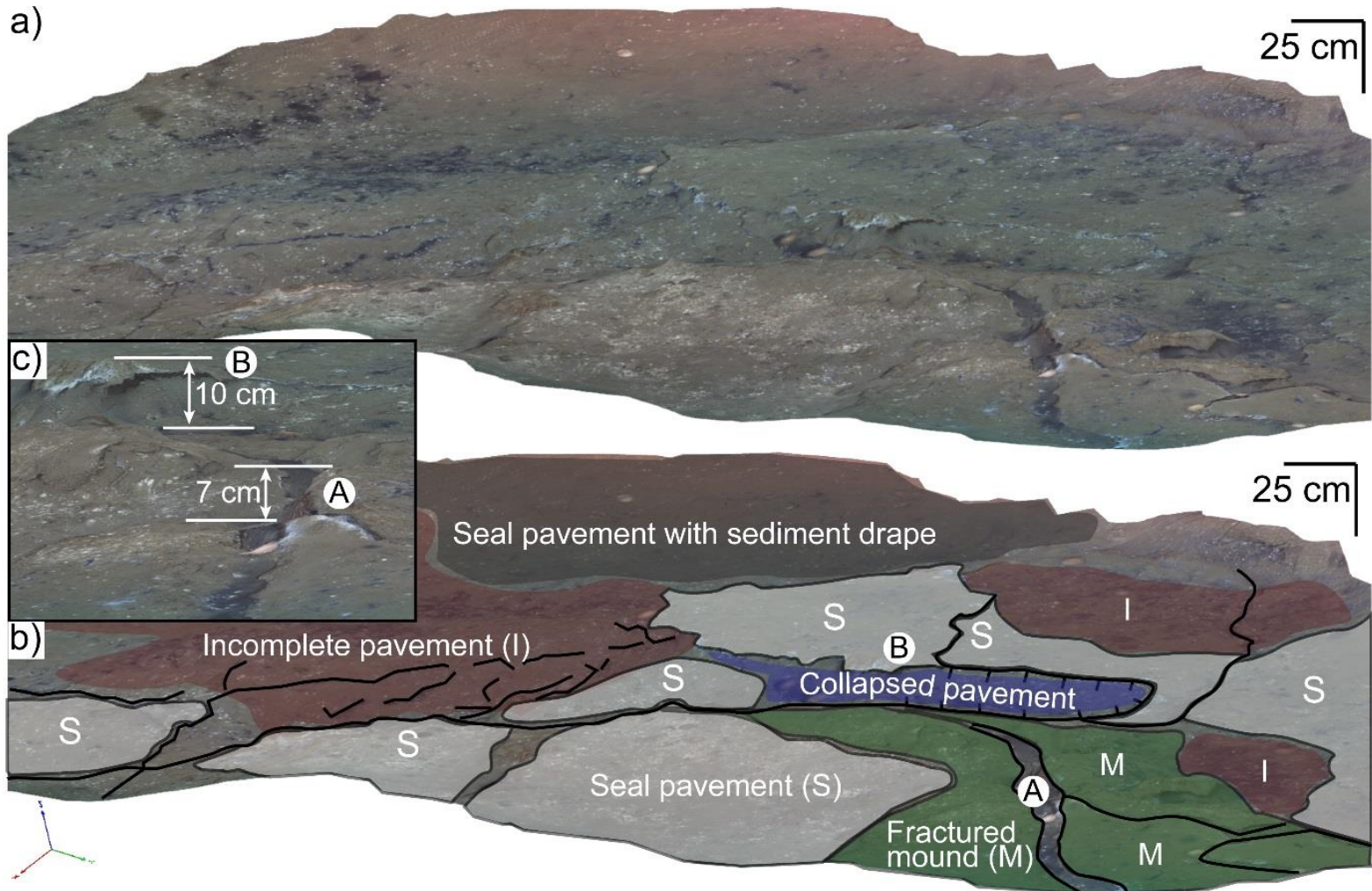

Figure 10. a: 3D-orthographic view at edge of photomosaic of Seep 1 (see Fig. 3c for extent and supplement S5 for movable turntable version); b: same as a) with interpretations, black lines indicate fractures or rims of carbonate slabs; c: enlargement around locations marked by $A$ ) and $B$ ) to show vertical offset by carbonate fracturing.

\subsection{Fluid sources contributing to composition and potential formation conditions of authigenic carbonate}

Authigenic carbonates record the stable carbon isotopic signature of the total dissolved $\mathrm{CO}_{2}$ (DIC) pool at the time of precipitation (Naehr et al. 2007). The DIC pool can comprise a mix of sources, including seawater (e.g. a typical value for eastern Mediterranean deep seawater of $\delta^{13} \mathrm{C}_{\mathrm{DIC}} \sim 1.2 \%$; (Pierre 1999)), oxidized organic matter (OM; $\delta^{13} \mathrm{C}_{\mathrm{OM}} \sim-23 \%$ ), oxidized methane (or higher hydrocarbons) depleted in ${ }^{13} \mathrm{C}\left(\delta^{13} \mathrm{C}_{\mathrm{HC}} \sim-110\right.$ to $-30 \%$; (Aloisi et al. 2000; Naehr et al. 2007), and fluids enriched in ${ }^{13} \mathrm{C}$ due to $\mathrm{CO}_{2}$ reduction in the methanogenic zone (Mozley and Burns 1993; Kopf et al. 1995; Greinert et al. 2001). Accordingly, authigenic carbonates may show high variability in their stable carbon isotope compositions (e.g. Greinert et al. (2001)). In contrast, all samples collected from the peripheral seeps at Venere MV show relatively low values of $\delta^{13} \mathrm{C}$ in a relatively narrow range of $-11.4 \%$ to $-27.1 \%$ o -PDB, with over $80 \%$ of all samples $<-19 \%$ (Fig. 9). These carbon 
isotopic compositions are consistent with methane as an important carbon source during precipitation of the predominantly aragonitic carbonates (Table 2), which is inferred to take place at shallow sediment depths during microbially-mediated AOM.

The carbon isotopic compositions of authigenic carbonates from seepage sites on a number of continental margins was summarized by Naehr et al. (2007), who found a broad range of $\delta^{13} \mathrm{C}$ values ( $-5 \%$ to $-58 \%$ PDB): the lower limit of this range (i.e. below $-40 \%$ ) can be attributed to the anaerobic oxidation of microbial methane, whereas values between $\sim-40$ and $-20 \%$ point to the anaerobic oxidation of methane from a thermogenic source with contributions from sedimentary OM or seawater-DIC. The majority of the samples presented in this study are therefore tentatively attributed to anaerobic oxidation of a thermogenic methane source, with lesser contributions from DIC dissolved in seawater and the oxidization of OM. Similar $\delta^{13} \mathrm{C}$-values of carbonate (i.e. in the broad range of $\sim-40$ and $-20 \%$ ) have been reported for authigenic carbonates from mud volcanoes and pockmarks in the Eastern Mediterranean (Gontharet et al. 2007; Himmler et al. 2011), assumed to have a predominantly thermogenic hydrocarbon source (Gontharet et al. 2007; Pape et al. 2010). At Venere $\mathrm{MV}$, this interpretation for the seep carbonates is further supported by the carbon stable isotopic composition of methane $\left(\delta^{13} \mathrm{C}=-48.6\right.$ and $\left.-47.3 \%\right)$ and higher molecular weight hydrocarbons such as ethane $\left(\delta^{13} \mathrm{C}-\mathrm{C}_{2} \mathrm{H}_{6}\right.$ of $-21.6 \%$ and $\left.-22.3 \%\right)$ and propane $\left(\delta^{13} \mathrm{C}\right.$ $\mathrm{C}_{3} \mathrm{H}_{8}$ of $-12.5 \%$ and $-17.7 \%$; (Blumenberg et al. 2017)) emitted at the peripheral seeps. Compared to the emitted methane gas, however, the seep carbonates show less negative $\delta^{13} \mathrm{C}$-values, which can be attributed to contributions from DIC dissolved in seawater and from the oxidization of buried organic matter (Peckmann and Thiel 2004; Himmler et al. 2015).

The stable oxygen isotope composition of authigenic carbonate is controlled by several factors, including the composition and temperature of the pore fluid from which precipitation occurs, as well as the mineralogy of the carbonate that forms. As a first approximation, the theoretical $\delta^{18} \mathrm{O}$ values of aragonite and $\mathrm{Mg}$-calcite (i.e. with $12 \mathrm{~mol} \% \mathrm{MgCO}_{3}$ ) should amount to, respectively, 3.3\% and 2.9\% V-PDB (Friedman and O'Neil 1977; Grossman and Ku 1986; Aloisi et al. 2000; Gontharet et al. 2007), on the assumption that precipitation occurred from eastern Mediterranean bottom waters in present-day conditions of temperature, $\mathrm{pH}$, and $\delta^{18} \mathrm{O}$. The average oxygen isotope compositions of each sample in this study range from 1.4 to $2.5 \% \mathrm{~V}$-PDB (Table 1). As these values are relatively depleted in ${ }^{18} \mathrm{O}$ (Fig. 9), the fluid source was either significantly warmer or depleted in ${ }^{18} \mathrm{O}$ (or a combination of both effects). Carbonates exposed to the oxygenated water column at sites of methane seepage may experience lower $\mathrm{pH}$ values during aerobic oxidation of methane and hydrogen 
sulfide (Himmler et al. 2011), argued to result in heavier $\delta^{18} \mathrm{O}$ values (Zeebe 2001; Han et al. 2004). The depleted $\delta^{18} \mathrm{O}$ signals recorded here indicate that changes in fluid $\mathrm{pH}$ values did not significantly affect the stable oxygen isotopes of the studied samples.

As aragonite is the predominant carbonate-forming mineral in the samples (Table 2), the temperatures of the fluid from which authigenic aragonite would precipitate were estimated (Table 1; see methods section), by assuming crystallization in equilibrium with the presentday regional bottom water $\delta^{18} \mathrm{O}$ value of $1.5 \%$ V-SMOW (Pierre 1999). Four of the six samples (from Sites 1,4 and 5) require fluid temperatures that are higher than the current bottom water by $0.3-3.8^{\circ} \mathrm{C}$, while two samples (both from Site 1) require fluid temperatures that are lower by $0.8^{\circ} \mathrm{C}$. Advection of warm fluids from the subsurface towards the peripheral seeps at Venere MV is indicated by geothermal gradients that are elevated relative to regional values, and lie in the range of $0.15-0.2^{\circ} \mathrm{C} / \mathrm{m}$ (Loher et al. in review). Alternatively, warmer temperatures imply that, for the four samples, aragonite precipitation would have to have occurred several meters below seafloor. However, this does not account for the two samples from Site 1 that indicate lower temperatures. Bottom water temperatures in the eastern Mediterranean Sea were up to $5{ }^{\circ} \mathrm{C}$ colder than present during the last glacial maximum (LGM) corresponding to an increase of $\delta^{18} \mathrm{O}$ values in bottom waters by $1.5 \%$ (Aloisi et al. 2000). In both cases (i.e. carbonate formation at sufficient depth or in the past), accumulated overlying sediments would have had to be removed, since all carbonate samples were collected close to or exposed at the seafloor. Given that Venere MV is located in a submarine canyon (Fig. 1c) which shows signs of repeated erosive sediment-transport events (Loher et al. 2018) such a scenario cannot be rejected. Alternatively, carbonate precipitation could have occurred from a fluid that had a temperature close to values measured today (i.e. $13.8^{\circ} \mathrm{C}$ ) but of different $\delta^{18} \mathrm{O}$ isotopic composition.

The stable oxygen isotope ratios of the water from which aragonite in the different samples may have precipitated have been calculated, assuming a formation temperature of $13.8^{\circ} \mathrm{C}$ (Table 1; see methods section). The results for most samples from sites 1, 4 and 5 suggest a composition depleted in ${ }^{18} \mathrm{O}$ by 0.1 to $0.9 \%$ V-SMOW, compared to the present-day bottom water $\delta^{18} \mathrm{O}$ value of $1.5 \%$ V-SMOW, while two samples from Site 1 indicate a fluid source slightly enriched in ${ }^{18} \mathrm{O}$ by $0.2 \% \mathrm{~V}$-SMOW. The water cage of gas hydrate preferentially incorporates the heavier oxygen isotope, causing the residual fluid source to be relatively depleted in ${ }^{18} \mathrm{O}$ (Ussler and Paull 1995). In contrast, the release of cage water in the course of gas hydrate dissociation leads to increase in $\delta^{18} \mathrm{O}$ by up to $+3 \%$ (Davidson et al. 1983; Bohrmann et al. 1998). The slightly higher ${ }^{18} \mathrm{O}$ values calculated for the fluids at Site 1 do not 
indicate a significant contribution from gas hydrate dissociation, whereas the more depleted signals could point to the formation of small amounts of gas hydrate.

\subsection{Mound formation mechanisms based on estimates of gas pressure}

Thin-plate theory has previously been applied analyzing the formation of circular mounds in soft solids in response to gas accumulations below a confining layer (Barry et al. 2012), extended to the buoyancy effect of gas underlying seafloor sediments (Koch et al. 2015). Although these studies focused on the deformation of a layer of soft solids, Barry et al. (2012) concluded that the same theory may be applied to stiff geomaterials such as cemented sediments. According to Barry et al. (2012) and Koch et al. (2015) the gas pressure $\left(P_{\text {def }}\right)$ needed for the formation of mound structures can be calculated by the following formula:

$P_{\text {def }}=\frac{8}{3} * \frac{E}{1-v} * \frac{h * w_{\max }}{a^{4}} *\left(\frac{2 h^{2}}{1+v}+w_{\max }^{2}\right)$

where $E$ is the Young's modulus, $v$ is Poisson's ratio, $h$ is the thickness, $w_{\max }$ is the maximum vertical displacement, and $a$ is the radius of the deformed sedimentary plate. The model by Koch et al. (2015) additionally accounts for the buoyancy force caused by the gas accumulation and the lithostatic pressure $\left(P_{\text {lit }}\right)$ of the sediment plate $\left(\rho_{\text {sediment }}{ }^{*} g{ }^{*} h\right)$ when calculating the gas column height $\left(\mathrm{h}_{\mathrm{g}}\right)$ equivalent to the respective gas pressure:

$h_{g}=\frac{\left(P_{\text {def }}-P_{\text {lit }}\right)}{g\left(\rho_{\text {water }}-\rho_{\text {gas }}\right)}(2)$

Koch et al. (2015) used values for $E$ and $v$ of up to $0.35 \mathrm{GPa}$ and 0.5 , respectively, to analyze dome formation in silty clay. Here a value similar to that of limestone (i.e. $E=30$ GPa; $v=0.33$ ) is used as a first approximation for the up to $20 \mathrm{~cm}$ thick layers cemented by authigenic carbonate observed in this study. To form mound geometries such as at Site 1 (a $=5 \mathrm{~m} ; \mathrm{h}=20 \mathrm{~cm} ; \mathrm{w}_{\max }=50 \mathrm{~cm}$; see Fig. $\left.3 \mathrm{c}\right)$ and Site $4\left(\mathrm{a}=2.5 \mathrm{~m} ; \mathrm{h}=20 \mathrm{~cm} ; \mathrm{w}_{\max }=50 \mathrm{~cm}\right.$; see Fig. $5 \mathrm{~b}$ ), gas pressures of $5.9^{\star} 10^{6} \mathrm{~Pa}$ and $9.5^{\star} 10^{7} \mathrm{~Pa}$, respectively, are required. Using a density of the carbonate crust of $2700 \mathrm{~kg} / \mathrm{m}^{3}$, a density of $1030 \mathrm{~kg} / \mathrm{m}^{3}$ for pore water, and an estimated porosity of $30 \%$ for the carbonate crust, the heights of the corresponding gas columns amount to $655 \mathrm{~m}$ at Site 1 and $10478 \mathrm{~m}$ at Site 4.

These results have large uncertainties, e.g. due to heterogeneities in cemented sediments not accounted for by thin-plate mechanics (Barry et al. 2012). Nonetheless, the calculated deformation pressures are several orders of magnitude larger than those calculated by Koch et al. (2015) for larger mounds (1.5 to $6.5 \mathrm{~m}$ high and over $300 \mathrm{~m}$ diameter) composed of silty clay. The large difference is mainly due to the greater stiffness (expressed by Young's modulus) of the carbonate material and the larger height/width ratio of the mounds. The pressures required at Sites 1 and 4 are likely too great to be supported by the surrounding 
(non-cemented) sediments, and would lead to hydrofracturing and bleeding of the gas column before mound formation could occur. In contrast, if deformation of non-cemented seafloor sediments is assumed (i.e. $\mathrm{E}=0.35 \mathrm{GPa}$ and $\mathrm{v}=0.5$ similar to Koch et al. (2015)), the required pressures and gas column heights are $9.1^{*} 10^{4} \mathrm{~Pa}$ and $10 \mathrm{~m}$ at Site 1 and $1.4{ }^{*} 10^{6} \mathrm{~Pa}$ and $161 \mathrm{~m}$ at Site 4 . However, with the available subbottom data (Loher et al. 2018) it is not possible to resolve the potential presence of a gas column at Venere MV.

These calculations suggest that while gas pressure could have allowed mounds to form in unconsolidated sediments including loose aggregates of authigenic carbonate such as at Site 4 (section 4.2 and Fig. 5f), gas pressures alone cannot account for the fracturing of solid carbonate pavements leading to tilted carbonate slabs (e.g. Site 1; Fig. 3d+e). Another possible mechanism for mound formation involves volume expansion due to the formation of gas hydrate in the pore space of sediments, a process suggested to form hydrate pingoes (Long et al. 1998; Hovland and Svensen 2006). Sediment doming by gas hydrate formation has been argued to require high gas hydrate saturations (Hovland and Svensen 2006; Koch et al. 2015; Sahling et al. 2016). The accumulation of gas hydrates below a cemented pavement could account for the observed fracturing of carbonate and upheaval of slabs (e.g. Site 1; Fig. 3d+e). The formation of gas hydrate can also act as a seal for fluid migration, reducing the fluid supply from below (Römer et al. 2012; Sultan et al. 2014). Subsequent slow dissolution of near-surface gas hydrate may take place, accounting for volume reduction and collapse, but also continuing to release methane-rich fluids so as to support AOM even after cessation of the underlying fluid supply (Sahling et al. 2008). Accordingly, if carbonate plates are fractured during the growth of the hydrate-cored mound they may be recemented by AOM-induced carbonate precipitation.

Seal-and-break mechanisms have been argued to explain the formation of pockmarks (Matsumoto 1990; Hovland 2002; Marcon et al. 2014a). The observations in this study, however, indicate that ruptures in mounds or pavements may be re-sealed without undergoing collapse. The mound at Site 1 hosts at least two generations of carbonates (Figs. $3 d+e): d m$-thick slabs that were ruptured and rifted apart by up-doming of the seafloor, and carbonates that partially re-seal the central part between the rifted slabs. Tube worms were observed aligned along the central rift as well as at the edges of the ruptured slabs, indicating persistent fluid supply through the mounded structure. Oxygen isotopic values in some authigenic carbonates in this study (Fig. 9) could be explained by coeval hydrate formation at the time of their precipitation. The inferred process of rupturing and re-sealing is likely to have occurred repeatedly and contributed to the convex-up shape of the mounds, with relatively younger carbonate slabs underplating the overlying ones (forming a stack of 
carbonate slabs). Furthermore, gas hydrate inside the mounds would support their positive morphology by cementation of subsurface sediments even after an initial rupture has occurred, as would carbonate growth in spaces vacated by hydrates. Upon complete depletion of the temporary gas hydrate reservoir in the mound, the carbonate plates may bend, fracture, and even collapse under their own weight, forming new fractures or cratershaped morphologies (Fig. 4e+5d+10).

Temperature gradients of $0.15-0.2^{\circ} \mathrm{C} / \mathrm{m}$ at the seepage sites allow for a thin $(<10 \mathrm{~m})$ gas hydrate stability zone (Loher et al. in review), and evidence of gas seepage both at the present-day and over the timescales of carbonate formation suggests that gas hydrates are likely to have formed. Small flakes of gas hydrate were observed during ROV operations at mounds with not yet fully consolidated carbonates (Fig. 5 and supplemental videos S1+S2). Mounds represent areas of greater thicknesses of carbonates (Fig. 3d+e; $5 b$ ) which also indicate higher or longer-term gas fluxes, and it is logical to think that these would also have favored gas hydrate formation within the mounds. Thus it is proposed that the observations of multiple generations of seals and fractures (Fig. $3 e+f$ ) and complex mound morphologies (Fig. $3 b$ ) can be explained through the dynamics of seafloor sealing, gas hydrate accumulation, mound formation, and subsequent collapse.

\subsection{A conceptual model of seep evolution}

\subsubsection{Stage A - "plain seepage"}

In this study, it is postulated that the initial stage of a cold-seep (Stage A of Fig. 11) is characterized by the continuous or pulsating release of gas bubbles from bioturbated hemipelagic sediments, a scenario that has been defined as "plain seepage" by Hovland (2002). At this stage, no other indicators of seepage, such as microbial mats or authigenic carbonates, are observed. Methane oversaturation with respect to pore water causes methane gas bubbles to grow and expand by processes of diffusion, leading in turn to the fracturing of sediments and the creation of pathways for the upward migration of bubbles (Boudreau 2012). The initial establishment of a physicochemical micro-environment that supports AOM has been argued to occur by microbial colonization of the emission site or potentially of the bubble pathways several centimeters in the subsurface (Hovland 2002). Strong advective flow of methane-enriched fluids and gas bubbles may largely bypass the AOM-performing communities so as to release methane to overlying water (Luff et al. 2004; Sommer et al. 2006). However, it has been observed that microbial methanotrophic mats can develop under anoxic conditions several $\mathrm{cm}$ below seafloor at sites of gas emissions (Treude et al. 2005). This implies that even if no microbial mats are visible at the seafloor at the stage of "plain seepage", AOM is likely still occurring close to the seafloor and can induce the initial 
precipitation of authigenic carbonate. The presence of microbial mats and the precipitation of AOM-induced carbonates within near-seafloor sediments impedes upward fluid flow and causes methane to spread into and charge surrounding sediments (Sassen et al. 1993; Hovland 2002).

\subsubsection{Stage B - microbial mats at the seafloor and first colonization by seep- organisms}

Gas rising in soft cohesive sediments may stall by spreading horizontally in zones of decreased lateral fracture toughness (Boudreau 2012), which forms the basis for the next stage of an evolving seep (Stage B in Fig. 11). This stage comprises the formation of patchy, black-colored, and reduced (anoxic) surface sediments (e.g. Fig. 6d) that are partially or fully covered by white filamentous microbial mats (Figs. $6 e+7 a, b, d$ ) and underlain by disseminated authigenic carbonate. Hovland (2002) also proposed the second stage of an evolving seep to be characterized by the appearance of microbial mats on the seafloor. In this study, however, mobile chemosynthesis-based organisms (e.g. vesicomyid clams; Fig. 7a) were also observed to colonize the seepage sites in the surroundings of intense white microbial mats (most likely sulfur-oxidizing bacteria such as Beggiatoa; Fig. $7 b+d$ ). In addition, the soft sediments available at this stage constitute a habitat for vesicomyid clams, which typically root in soft sediments to access AOM-derived sulfide (Sahling et al. 2002). The onset of carbonate precipitation in the uppermost $\mathrm{cm}$ of sediments at this stage may start to influence fluid migration pathways (Feng and Roberts 2010) leading to discrete ebullition sites where gas oversaturation is reached.

\subsubsection{Stage $\mathbf{C}$ - self-sealing and mound formation}

Stage C (Fig. 11) involves formation of extensive carbonate pavements and (partially) sealed mounds (Figs. $5 a+e+f$ ). Gas accumulations may start to deform the unconsolidated seafloor by increasing pressure and the buoyancy force in the subsurface, as discussed in section 5.3 . Upward gas flux may also result in gas hydrate accumulations, leading to a volume increase in the pore space and inducing mound formation. In any case, hydrocarbon seepage and AOM-induced carbonate precipitation will facilitate the cementation of mound structures. Intact carbonate crusts form a seal at the sediment-water interface, which prevents the release of hydrocarbon-bearing fluids and the downward diffusion of seawater-derived sulfate, and so inhibit $\mathrm{AOM}$ and further carbonate precipitation. The carbonates may also serve as a physical and chemical barrier, e.g. to vesicomyid clams who live partially embedded in soft sediments. The large numbers of empty clam shells littering the surface of the carbonate pavements (e.g. Fig. 4e) may be explained by progressive carbonate cementation and exclusion of the clams from their habitat (Bohrmann et al. 2015). 
Several of the observed high backscatter patches are of circular or ovoid shape (Figs. 3a, 4a, 5a) and host thick (up to several $\mathrm{dm}$ ) carbonate deposits in their central areas, whereas, thinner or discontinuous carbonates exist at the edges. The mounds observed in this study are interpreted to represent the surface expressions for focused upward migration of fluids. They most likely contain a mixture of hydrocarbon-rich pore water, free gas, and small amounts of disseminated gas hydrate underneath the carbonate pavements. Gas spreads laterally underneath this carbonate or gas hydrate seal and emanates as gas bubbles from cracks or along the edges of the carbonate pavement up to several meters from the mounds (Fig. 5f).

\subsubsection{Stage D - ruptured carbonate mounds}

At Stage D (Fig. 11), fluid escape into bottom waters occurs through discrete ruptures in the carbonate crusts, in the form of free gas bubbles and gas dissolved in pore fluids. The seepage sites are characterized by ruptured carbonate mounds with decimeter-thick crusts and significant numbers of chemosynthesis-based organisms (Figs. 3d, 6g, 7e). These structures are interpreted to represent the most mature stage of the peripheral seeps at Venere MV. Well-developed chemosynthesis-based communities and ongoing gas bubble emissions indicate persistent subsurface fluid supply at all the peripheral seeps (Figs. 5+6). Given excessively high gas pressures required for the formation of mounds in carbonate pavements (see discussion in section 5.3), it is unlikely that the ruptured carbonate mounds resulted from gas pressure alone. Pore volume increase due to the accumulation of gas hydrate is suggested to contribute to the upheaval and fracturing of the carbonate plates. Subsurface accumulations of gas or gas hydrate may also allow AOM to be sustained during phases when fluid supply has ceased. Furthermore, once the gas hydrate or free gas accumulation has dissipated the carbonate plates may collapse under their own weight, representing an additional mechanism by which carbonates are fractured.

The overall morphology of the mounds described here resembles seepage-associated carbonate slabs observed by Römer et al. (2014) on the Nile Deep Sea Fan. Those structures are larger and higher than the mounds described at Venere MV, but also consist of ruptured authigenic carbonates with gas bubble emissions from the fractures and chemosynthesis-based organisms thriving at the fractures along the edges of the structures. We suggest, that the observations of Römer et al. (2014) support a similar dynamic for the evolution of seeps as the one we propose for the peripheral seeps of Venere MV during stage $D$.

The progressive precipitation of authigenic carbonate beneath the seafloor implies a decreasing number of voids or conduits through which the methane flow at cold seeps is 
channeled (Feng and Roberts 2010). In addition newly developed fractures in the carbonate mounds described here are inferred to allow seawater-derived sulfate to infiltrate the subsurface of the mounds, providing an electron acceptor source for AOM (see also Bahr et al. (2010)). This supports the re-establishment of chemosynthesis-based organisms such as vesicomyid clams and tube worms along the fractures in the carbonates (Fig. 7g). Such a scenario is consistent with observations of ruptured mounds where microbial mats cover the edges of carbonate crusts, vestimentiferan tube worms root below the mounds in the cracks (Figs. $6 g+7 e-g$; supplementary video S4), and vesicomyid clams inhabit the softer sediments that accumulated in between carbonate slabs. Vestimentiferan tube worms depend on sulfide fluxes that are an order of magnitude higher than those for vesicomyid clams (Sahling et al. 2002; Cordes et al. 2003). It has been found that tube worms are capable of fueling or selfenhancing $\mathrm{AOM}$ by transporting seawater-derived sulfate through their tubes and releasing it at their root-like extensions (Cordes et al. 2005). This process is thought to contribute to carbonate formation (Marcon et al. 2014b), in particular by developing a sulfate-enriched environment that favors the precipitation of aragonite over calcite (Feng et al. 2013). As a result of this process affecting the tube-worm tubes and due to their sessile nature, the tubeworms may be cemented into carbonate crusts (Haas et al. 2009). In this study, the occurrence of colonies of vestimentiferan tube worms at ruptures in the mounds, and the presence of their encrusted remains in carbonate samples (GeoB19230-8; Fig. 8), are interpreted as signs of intensive $\mathrm{AOM}$ generating $\mathrm{H}_{2} \mathrm{~S}$-rich fluids and indicate a persistent supply of hydrocarbon-rich fluids beneath the mounds. Carbonate samples from Site 1 exhibit the highest aragonite contents (Table 2) but appear to lack abundant pure aragonite phases which would be typical of tubeworm-associated carbonates (Feng et al. 2013). Seafloor observations of the sampling sites (Fig. $3 d+e$ ) rather suggest a mixed ecosystem environment (Feng and Roberts 2010) involving microbial mats, vesicomyid clams, as well as tubeworms. The carbonate fractures constitute a strongly localized habitat where microbial consortia and seep-typical macrofauna can flourish, profiting from the protection and stability provided by cementation of the carbonate crusts above or around them.

\subsubsection{Stage E - collapse craters}

Another type of seafloor structure (Stage $E$ in Fig. 11) resulting from rupturing of the carbonate pavement occurs where the carbonate-paved seafloor has collapsed and formed convex-down, crater-like depressions (Figs. 4e+5d). In marine sediments, different mechanisms have been proposed to account for the formation of pockmarks during gas ebullition either through sediment loss and non-deposition (King and MacLean 1970; Hovland et al. 1984) or through fluid flow and subsurface sediment mobilization (Maltman and Bolton 2003; Loher et al. 2016). Alternatively, persistent fluid flow underneath a 
carbonate crust formation can induce its collapse and fragmentation through a process referred to as "undermining" by Matsumoto (1990) but this author does not explain if this process includes the physical removal of sediment. At the peripheral seeps of Venere MV, neither the crater morphology nor that of the surrounding seafloor indicate a sediment expulsion event. Instead, the arrangement of broken slabs of carbonate lining the inside of sub-circular craters suggests an inward collapse and down-sagging of the seafloor. Collapse without the removal of sediment requires the presence of a subsurface void. Such voids may form when gas-rich fluids intrude into fine-grained sediments, push the sediment grains apart, and thus cause compaction of the pore space (Hantschel and Kauerauf 2009; Jain and Juanes 2009). A study by O'Regan et al. (2015) indicates that the formation of seafloor depressions can also occur through compaction following mobilization (without removal) of sediments. Those authors have shown in numerical models that subsurface overpressure resulted in the mobilization of sediments and large settlements (up to 35\% reduction in volume) occurred in the remolded sediments when the overpressure dissipated. The craters observed in this study are interpreted to result from collapse of carbonate pavements due to the release of fluid or gas hydrate accumulations beneath them. The slow or sudden fluid release generates a void and causes overpressure to dissipate and any potential buoyancy force upholding the carbonates to recede. Subsequently the overlying carbonates collapse under their own weight.

Similar to the process described by Bahr et al. (2010), it is assumed that breaking of carbonates occurs by brittle deformation as progressive cementation increases the rigidity of sediments. Samples obtained from the ruptured mound at Site 1 (GeoB19205-2; GeoB19230-8; GeoB19230-9) show massive cement with little incorporation of hemipelagic sediments (Fig. 8; Table 2). In contrast, the sample from the collapse crater near Site 4 (GeoB19252-13) contains abundant hemipelagic sediment, is only weakly cemented, and crumbles easily by hand. A more homogeneous cementation as in the samples from Site 1 is interpreted to result in a stronger carbonate slab whereas incorporation of hemipelagic sediments and biogenic remains gives rise to a weaker carbonate pavement. A stronger, more stable carbonate at Site 1 would explain why the mound did not collapse upon rupturing, whereas a collapse-crater formed near Site 4 . Intermittent gas bubble release, microbial mats, and tube-worm colonies (Figs. $4 e+5 d$ ) are signs of ongoing seepage at the collapsed craters. Whether this represents residual seepage from the rupturing event, the dissolution of residual gas hydrate, or a younger reactivation of the underlying fluid migration pathway, remains unclear. 


\subsection{Timescales of cold-seep evolution}

Whereas the processes of $\mathrm{AOM}$ and associated carbonate precipitation at cold seeps are relatively well understood, little is known about their timescales of development. U/Th-series have been successfully used to date cold-seep carbonates (Teichert et al. 2003; Bayon et al. 2009; Sauer et al. 2017), but this requires non-trivial correction procedures where detrital sediment such as clays are incorporated during the cementation process (Bayon et al. 2009). Absolute dating of carbonates is beyond the scope of this study and problematic given the complexity of the carbonate mineralogy (see e.g. sample GeoB19252-13, Table 2) and the absence of massive cement phases. Nevertheless, the temporal evolution of the seeps studied here can be constrained by order of magnitude estimates based on seafloor observations and seep-related processes described in the literature. This allows it to infer the interaction of processes operating over timescales from decades to millennia, as illustrated in Fig. 11

The establishment of a microbial AOM community in sediments and the growth kinetics of microbial mats have been investigated by modeling of bioenergetic reactions indicating that a steady-state AOM biomass can be reached on the order of 60 years after a change in advective flow (Dale et al. 2008; Knittel and Boetius 2009). Accordingly, it is estimated that it takes up to several tens of years from the onset of seepage in hemipelagic sediment (i.e. plain seepage as in Stage A, Fig. 11) to the formation of black reduced surface sediments and colonization by chemosynthesis-based organisms, assuming a constant supply of hydrocarbon-rich fluid. In this study, this would include the establishment of extensive (several $\mathrm{m}^{2}$ ) white microbial mats on the seafloor and settlement by chemosynthesis-based macrofauna (Stage B in Fig.11). Growth rates may vary significantly, however, as the typically localized or patchy distribution of microbial mats or chemosynthesis-based macrofauna at cold seeps depends strongly on the intensity of methane seepage and the sulfide concentration (Sahling et al. 2002). Nevertheless, similar estimates have been obtained from hydrocarbon seeps in the Gulf of Mexico, at water depths ca. $1000 \mathrm{~m}$ shallower than Venere MV, where chemosynthesis-based communities have been found to take tens of years to reach maturity (Nix et al. 1995). This is less than the estimated lifespan of vestimentiferan tube worms such as of Lamellibrachia sp. which in established colonies can reach 100-150 years (Fisher et al. 1997; Southward et al. 2011). At Venere MV, the mature tube worm colonies observed at Sites 1 and 4 along ruptures in the carbonates are therefore inferred to be at least tens to hundreds of years old, in turn implying the fractures they populate to be of similar age. These inferences are consistent with numerical models showing that disseminated carbonate pieces or crusts of few centimeter thickness take at least several centuries to develop (Luff et al. 2004), while the growth of massive (dm-thick) 
authigenic carbonate crusts may take place over longer timescales, at rates of up to $5 \mathrm{~cm} / \mathrm{kyr}$ (Bayon et al. 2009). Accordingly, the ruptures and visibly exposed carbonate crusts of $>20$ $\mathrm{cm}$ thickness described in this study (e.g. Fig. 4+7), indicate that seepage has persisted throughout the last thousands of years, accompanying mud breccia discharge from Venere MV (Loher et al. 2018).

At Venere MV, the fluid supply from depth occurs along ring faults connecting to the MV plumbing system (Loher et al. 2018), and appears to govern overall seepage activity. However, three main factors independent of a mud volcano plumbing system are suggested to control the seep evolution at the surface (Fig. 11) over different timescales: fluid migration, accumulation, and release. At short timescales (decades to centuries) the seep evolution and colonization is primarily driven from below by factors controlling focused fluid migration in the subsurface leading to the emission of hydrocarbon-rich fluids from hemipelagic sediments. Over longer timescales (centuries to millennia), as carbonates develop and act as a seal, the seep evolution is affected by trapping of fluids and their release through fractures or along the edges of carbonate structures. Thus over longer timescales, there is an interaction between the fluid migration from depth and the modifications caused by seepage in the nearseabed. It appears that the development of the seep structures in this study result from the dynamics of the seep system itself. Such a common yet overlooked process could account for the strong variations of the fluid flow intensity in space and time which are inherent to the nature of cold seeps. 
Fig. 11
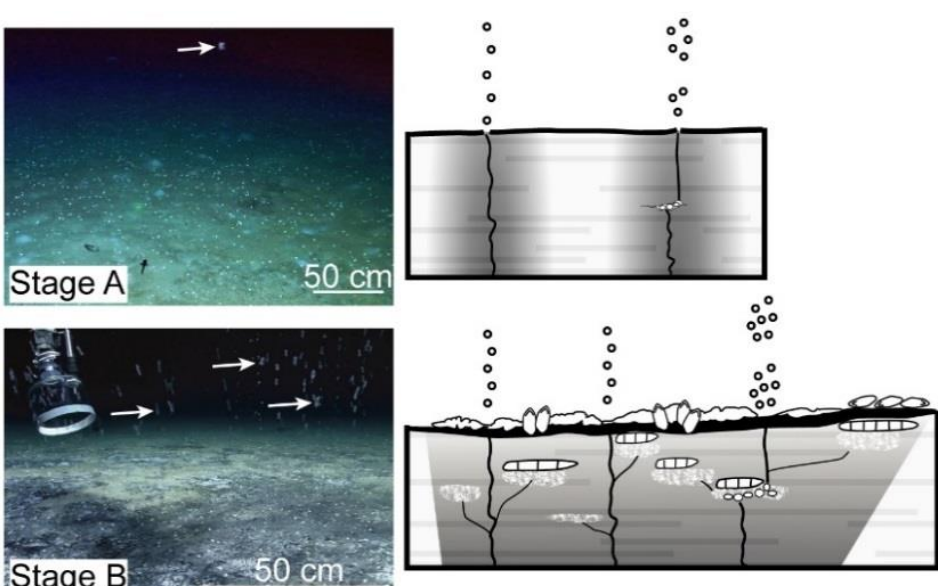

10s of

years
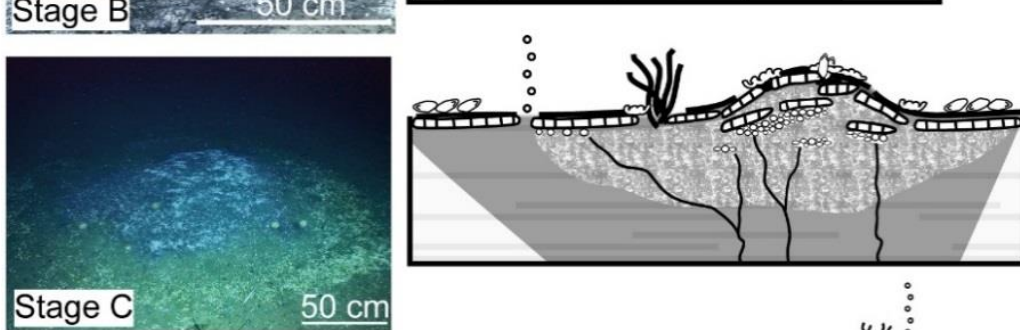

Centennial scale
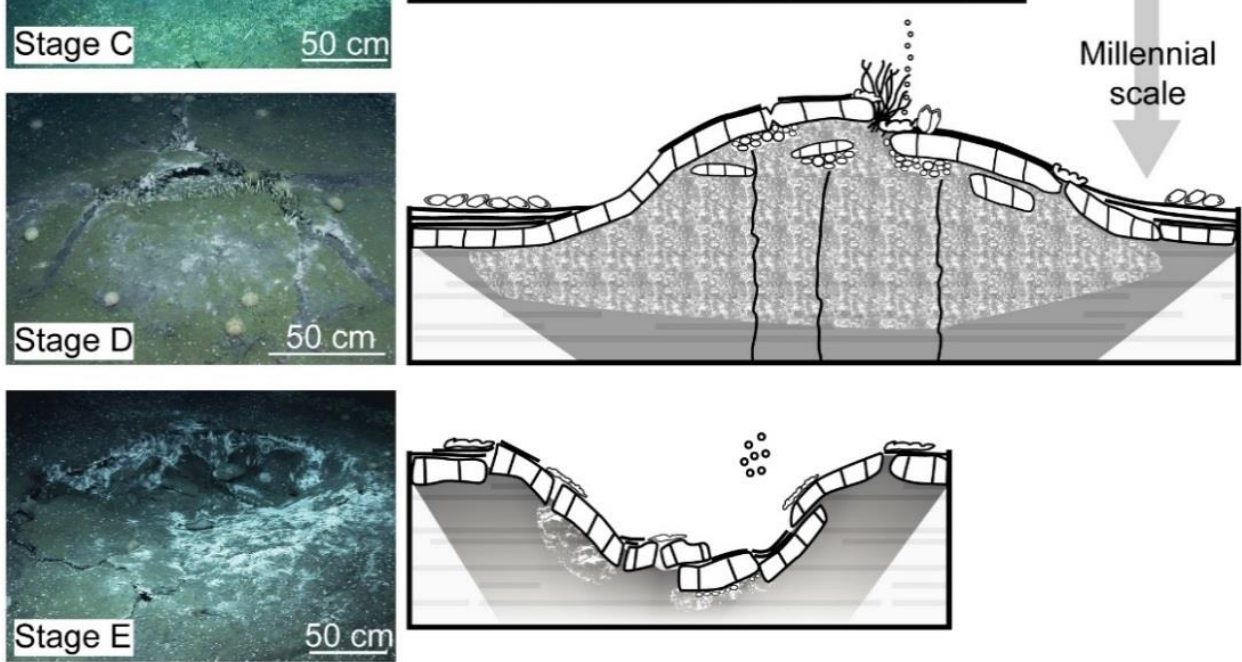

\section{Legend}

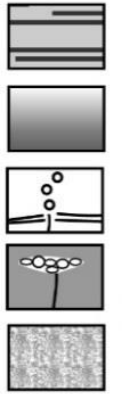

Sediment

Diffusive methane flux

Advective methane flux

Trapped gas bubbles in methane saturated subsurface

Gas hydrate in methane saturated subsurface TD Methane-derived authigenic

\begin{tabular}{|l|l|l|l|l|l|l|l}
\hline 0 & Alive / dead vesicomyid clams
\end{tabular} on sulfidic black sediments

White filamentous mats

Vestimentiferan tube worms

Figure 11: Conceptual model for the evolution of carbonate structures and chemosynthesisbased communities based on observations at the peripheral seeps of Venere MV inferred to be consistent with decadal to millennial timescales. White arrows in seafloor photos point to rising gas bubbles. 


\section{Conclusions and outlook}

Four sites of seafloor fluid seepage along faults peripheral to Venere MV were investigated through an integration of multi-parameter methods including AUV-borne multibeam surveys, ROV-based photomosaics and video observations and sampling. All sites are characterized by high acoustic seafloor backscatter patches up to $130 \mathrm{~m}$ wide, found to correspond to authigenic carbonate deposits that are colonized by chemosynthesis-based organisms known to be associated with microbially-mediated AOM. The investigated cold-seep sites include a range of flat, positive, and negative morphologies, the most complex of which are multi-generation mounds with fractured surfaces. The mineralogy and bulk stable carbon isotopic compositions of the carbonates are consistent with methane supply from below as the predominant carbon source. Sites of gas bubble release were observed from the carbonates and at their edges through hemipelagic sediments, indicating localized methane oversaturation and focused fluid flow. All sites investigated lie within the methane hydrate stability zone and gas trapped beneath carbonate deposits is presumed to form hydrate locally in the subsurface. Based on mechanical considerations and the properties of carbonate it is found that fluid overpressure build-up in response to carbonate precipitation is not enough to cause mound formation but it is likely that pore-volume expansion due to gas hydrate accumulation contributed to the fracturing of carbonate pavements.

The varied expressions of seepage observed are used to propose a conceptual model for the evolution of seep settings, involving five possible stages:

A) Plain seepage through bioturbated, hemipelagic sediments, with gas bubble release from small orifices.

B) Black patches and filamentous microbial mats develop within sediments hosting disseminated carbonate pieces or thin crusts, and localized gas bubble release. Persistent seepage over several tens of years is required for this development stage.

C) Carbonate pavements partly seal the seafloor, but fluid migration through cracks and at the edges of the pavements sustains microbial mats and the development of chemosynthesis-based communities. Free gas is trapped due to carbonate growth and leads to gas hydrate formation. Both processes contribute to pressure build-up and the formation of mounded morphologies on the seafloor. Persistent seepage over hundreds of years is required to reach this stage.

D) Carbonate mounds develop in response to subsurface pressure build-up by gas accumulation and pore-volume expansion by gas hydrate formation. They comprise dm-thick, fractured but strongly cemented slabs. Fractures result from brittle failure and allow 
seawater-derived sulfate to infiltrate and sustain chemosynthesis-based organisms such as tube worms which root beneath the carbonate slabs. Carbonate cementation may re-seal the mounds. Mound development is estimated to require several thousand years.

E) Collapse depressions lined by fractured carbonate slabs evolve due to release of trapped gas and dissolution of gas hydrate at the fractures. Colonization by chemosynthesis-based organisms indicates resumed seepage within several tens to hundreds of years.

This model for the evolution of cold seeps is applicable to other cold seep structures, for example those observed at the Nile Deep Sea Fan. Changes in fluid flow, gas accumulation, and pressure release are the three factors inferred to control the evolution of seafloor expression of seepage. In the case of Venere MV, this is inferred to occur primarily in response to carbonate precipitation and secondarily in response to gas hydrate formation and dissolution.

This study demonstrates the utility of state-of-the art seafloor investigations using AUV-borne acoustic technologies in combination with ROV-based photomosaics and video surveys to study cold-seep structures in their entirety. A focus can be put on detailed, areal seafloor investigations and sampling at the most active sites of fluid release in contrast to more traditional investigations which are limited to visualizing narrow strips across large targets. Although beyond the scope of this study, analyses of 3D-photomosaics may provide the basis for future investigations that focus on quantitative aspects of hydrocarbon release at cold seeps, such as carbon flux into the water column or storage as authigenic carbonates. Furthermore there remain uncertainties regarding the mechanical processes involved in fracturing and collapse of authigenic carbonate structures, which may be addressed by dedicated modeling efforts. The results of this study help to interpret seep sites encountered during visual seafloor exploration and highlight the extent and dynamics of seafloor mounds or craters formed in association with gas release from marine sediments.

\section{Acknowledgements}

The authors are grateful for the efforts of the masters and crews of cruises RV METEOR M112 and RV POSEIDON POS499. The teams of the MARUM AUV SEAL 5000 and ROV QUEST $4000 \mathrm{~m}$ are also thanked for their efforts during both cruises. Jonas Brünjes is acknowledged for carbonate sample preparation and their initial description. The Deutsche Forschungsgemeinschaft (DFG) and the Research Center / Excellence Cluster "The Ocean in the Earth System" are acknowledged for funding of expeditions M112 and POS499. We thank C. Vogt (Research Group Crystallography, Department of Geoscience, University of Bremen) for analysis of carbonate mineralogy and $\mathrm{H}$. Kuhnert (MARUM, Stable Isotope 
Laboratory) for analysis of carbonate bulk $\mathrm{C}$ and $\mathrm{O}$ stable isotopes. Marta Torres acknowledges support through a fellowship from the Hanse Wissenschaftskolleg. Daniel Praeg acknowledges funding from the European Union's Horizon 2020 research and innovation program under the Marie Skłodowska-Curie grant agreement No 656821 (project SEAGAS). Supplementary videos, a 3D-turntable .pdf version of Fig. 10, and enlarged seafloor photos are attached to this manuscript and the photomosaics will be made available via Pangaea (www.pangaea.de) upon acceptance of this manuscript.

\section{References}

Aloisi G, Pierre C, Rouchy J-M, Foucher J-P, Woodside J, Party MS (2000) Methanerelated authigenic carbonates of eastern Mediterranean Sea mud volcanoes and their possible relation to gas hydrate destabilisation Earth Planet Sc Lett 184:321-338

Bahr A, Pape T, Abegg F, Bohrmann G, van Weering T, Ivanov MK (2010) Authigenic carbonates from the eastern Black Sea as an archive for shallow gas hydrate dynamics - Results from the combination of CT imaging with mineralogical and stable isotope analyses Mar Petrol Geol 27:1819-1829 doi:10.1016/j.marpetgeo.2010.08.005

Bahr A, Pape T, Bohrmann G, Mazzini A, Haeckel M, Reitz A, Ivanov M (2007) Authigenic carbonate precipitates from the NE Black Sea: a mineralogical, geochemical, and lipid biomarker study Int $J$ Earth Sci 98:677 doi:10.1007/s00531-007-0264-1

Barnes RO, Goldberg ED (1976) Methane Production and Consumption in Anoxic Marine-Sediments Geology 4:297-300 doi:10.1130/00917613(1976)4<297:Mpacia>2.0.Co;2

Barry MA, Boudreau BP, Johnson BD (2012) Gas domes in soft cohesive sediments Geology 40:379-382 doi:10.1130/G32686.1

Bayon G, Henderson GM, Bohn M (2009) U-Th stratigraphy of a cold seep carbonate crust Chem Geol 260:47-56 doi:10.1016/j.chemgeo.2008.11.020

Birgel D, Feng D, Roberts HH, Peckmann J (2011) Changing redox conditions at cold seeps as revealed by authigenic carbonates from Alaminos Canyon, northern Gulf of Mexico Chem Geol 285:82-96 doi:10.1016/j.chemgeo.2011.03.004

Blumenberg M, Pape T, Seifert R, Bohrmann G, Schlömer S (2017) Can hydrocarbons entrapped in seep carbonates serve as gas geochemistry recorder? Geo-Mar Lett doi:10.1007/s00367-017-0522-6

Bohrmann G et al. (2015) Report and preliminary results of R/V METEOR cruise M112, Dynamic of Mud Volcanoes and Seeps in the Calabrian Accretionary Prism, Ionian Sea, Catania (Italy) - Catania (Italy), November 6 - December 15, 2014 Berichte, MARUM - Zentrum für Marine Umweltwissenschaften, Fachbereich Geowissenschaften, Universität Bremen No. 306:217

Bohrmann G, Greinert J, Suess E, Torres M (1998) Authigenic carbonates from the Cascadia subduction zone and their relation to gas hydrate stability Geology 26:647-650 doi:Doi 10.1130/0091-7613(1998)026<0647:Acftcs>2.3.Co;2 
Boudreau BR (2012) The physics of bubbles in surficial, soft, cohesive sediments Mar Petrol Geol 38:1-18 doi:10.1016/j.marpetgeo.2012.07.002

Buerk D, Klaucke I, Sahling H, Weinrebe W (2010) Morpho-acoustic variability of cold seeps on the continental slope offshore Nicaragua: Results of fluid flow interaction with sedimentary processes Mar Geol 275:53-65 doi:10.1016/j.margeo.2010.04.007

Caress DW, Chayes DN (1996) Improved processing of Hydrosweep DS multibeam data on the R/V Maurice Ewing Marine Geophysical Researches 18:631-650 doi:10.1007/bf00313878

Ceramicola S, Praeg D, Cova A, Accettella D, Zecchin M (2014) Seafloor distribution and last glacial to postglacial activity of mud volcanoes on the Calabrian accretionary prism, Ionian Sea Geo-Mar Lett 34:111-129 doi:10.1007/s00367013-0354-y

Cordes EE, Arthur MA, Shea K, Arvidson RS, Fisher CR (2005) Modeling the mutualistic interactions between tubeworms and microbial consortia PLOS Biology 3:e77

Cordes EE, Bergquist DC, Shea K, Fisher CR (2003) Hydrogen sulphide demand of long-lived vestimentiferan tube worm aggregations modifies the chemical environment at deep-sea hydrocarbon seeps Ecology Letters 6:212-219

Crémière $A$ et al. (2016) Fluid source and methane-related diagenetic processes recorded in cold seep carbonates from the Alvheim channel, central North Sea Chem Geol 432:16-33 doi:10.1016/j.chemgeo.2016.03.019

Dale AW, Van Cappellen P, Aguilera DR, Regnier P (2008) Methane efflux from marine sediments in passive and active margins: Estimations from bioenergetig reaction-transport simulations Earth Planet Sc Lett 265:329-344 doi:10.1016/j.epsl.2007.09.026

Davidson DW, Leaist DG, Hesse R (1983) Oxygen-18 enrichment in the water of a clathrate hydrate Geochim Cosmochim Ac 47:2293-2295 doi:10.1016/00167037(83)90053-4

de Beer D et al. (2006) In situ fluxes and zonation of microbial activity in surface sediments of the Hakon Mosby Mud Volcano Limnol Oceanogr 51:1315-1331 doi:DOI 10.4319/lo.2006.51.3.1315

Dillon WP, Nealon JW, Taylor MH, Lee MW, Drury RM, Anton CH (2001) Seafloor Collapse and Methane Venting Associated with Gas Hydrate on the Blake Ridge: Causes and Implications to Seafloor Stability and Methanerelease. In: Natural Gas Hydrates: Occurrence, Distribution, and Detection. American Geophysical Union, pp 211-233. doi:10.1029/GM124p0211

Dupré S, Woodside J, Klaucke I, Mascle J, Foucher JP (2010) Widespread active seepage activity on the Nile Deep Sea Fan (offshore Egypt) revealed by highdefinition geophysical imagery Mar Geol 275:1-19 doi:10.1016/j.margeo.2010.04.003

Feng D, Cordes EE, Roberts HH, Fisher CR (2013) A comparative study of authigenic carbonates from mussel and tubeworm environments: Implications for discriminating the effects of tubeworms Deep-Sea Res Pt I 75:110-118 doi:10.1016/j.dsr.2013.02.002 
Feng D, Peng YB, Bao HM, Peckmann J, Roberts HH, Chen DF (2016) A carbonatebased proxy for sulfate-driven anaerobic oxidation of methane Geology 44:999-1002 doi:10.1130/G38233.1

Feng D, Roberts HH (2010) Initial results of comparing cold-seep carbonates from mussel- and tubeworm-associated environments at Atwater Valley lease block 340, northern Gulf of Mexico Deep-Sea Res Pt li 57:2030-2039 doi:10.1016/j.dsr2.2010.05.004

Fisher CR, Urcuyo IA, Simpkins MA, Nix E (1997) Life in the slow lane: growth and longevity of cold-seep Vestimentiferans Marine Ecology 18:83-94

Friedman I, O'Neil JR (1977) Compilation of stable isotope fractionation factors of geochemical interest U S Geol Surv Prof Pap 440-KK US Geological Survey, Reston, VA

Goldsmith JR, Graf DL, Heard HC (1961) Lattice Constants of the CalciumMagnesium Carbonates Am Mineral 46:453-457

Gontharet $S$ et al. (2007) Nature and origin of diagenetic carbonate crusts and concretions from mud volcanoes and pockmarks of the Nile deep-sea fan Deep-Sea Reseach II 54:1292-1311

Greinert J, Bohrmann G, Suess E (2001) Gas hydrate-associated carbonates and methane-venting at Hydrate Ridge: Classification, distribution, and origin of authigenic lithologies. In: Natural Gas Hydrates: Occurence, Distribution, and Detection, vol 124. Geophysical Monograph, pp 99-113

Grossman E, Ku T (1986) Oxygen and carbon isotope fractionation in biogenic aragonite: Temperature effects vol 59. doi:10.1016/0168-9622(86)90057-6

Gueguen E, Doglioni C, Fernandez M (1998) On the post-25 Ma geodynamic evolution of the western Mediterranean Tectonophysics 298:259-269 doi:10.1016/S0040-1951(98)00189-9

Gutscher M-A et al. (2017) Active tectonics of the Calabrian subduction revealed by new multi-beam bathymetric data and high-resolution seismic profiles in the Ionian Sea (Central Mediterranean) Earth Planet Sc Lett 461:61-72 doi:10.1016/j.epsl.2016.12.020

Haas A, Little CTS, Sahling H, Bohrmann G, Himmler T, Peckmann J (2009) Mineralization of vestimentiferan tubes at methane seeps on the Congo deepsea fan Deep Sea Reseach 56:283-293 doi:10.1016/j.dsr.2008.08.007

Han X, Suess E, Sahling H, Wallmann K (2004) Fluid venting activity on the Costa Rica Margin: new results from authigenic carbonates Int J Earth Sci 93:596611 doi:10.1007/s00531-004-0402-y

Hantschel T, Kauerauf Al (2009) Pore Pressure, Compaction and Tectonics; In: Fundamentals of Basin and Petroleum Systems Modeling. Springer-Verlag Berlin Heidelberg. doi:10.1007/978-3-540-72318-9 2

Himmler T, Birgel D, Bayon G, Pape T, Ge L, Bohrmann G, Peckmann J (2015) Formation of seep carbonates along the Makran convergent margin, northern Arabian Sea and amolecular and isotopic approach to constrain the carbon isotopic composition of parent methane Chem Geol 415:102-117 doi:10.1016/j.chemgeo.2015.09.016 
Himmler T, Brinkmann F, Bohrmann G, Peckmann J (2011) Corrosion patterns of seep-carbonates from the eastern Mediterranean Sea Terra Nova 23:206-212 doi:10.1111/j.1365-3121.2011.01000.x

Hovland M (2002) On the self-sealing nature of marine seeps Cont Shelf Res 22:2387-2394 doi:Doi 10.1016/S0278-4343(02)00063-8

Hovland M, Judd AG, King LH (1984) Characteristic features of pockmarks on the North Sea floor and Scotian shelf Sedimentology 31:471-480

Hovland M, Svensen H (2006) Submarine pingoes: Indicators of shallow gas hydrates in a pockmark at Nyegga, Nrowegian Sea Mar Geol 228:15-23

Huguen C, Mascle J, Woodside J, Zitter T, Foucher JP (2005) Mud volcanoes and mud domes of the Central Mediterranean Ridge: Near-bottom and in-situ observations Deep-Sea Research Part 1 52:1911-1931

lannace A et al. (2007) The carbonate tectonic units of northern Calabria (Italy): a record of Apulian palaeomargin evolution and Miocene convergence, continental crust subduction, and exhumation of HP-LT rocks J Geol Soc London 164:1165-1186 doi:10.1144/0016-76492007-017

Jain AK, Juanes R (2009) Preferential Mode of gas invasion in sediments: Grainscale mechanistic model of coupled multiphase fluid flow and sediment mechanics J Geophys Res-Sol Ea 114 doi:10.1029/2008jb006002

Jerosch K, Schlüter M, Foucher J-P, Allais A-G, Klages M, Edy C (2007) Spatial distribution of mud flows, chemoautotrophic communities, and biogeochemical habitats at Håkon Mosby Mud Volcano Mar Geol 243:1-17

King LH, MacLean B (1970) Pockmarks on the Scotian shelf Geol Soc Am Bull $81: 3141-3148$

Klaucke I, Sahling H, Weinrebe W, Blinova V, Burk D, Lursmanashvili N, Bohrmann $G$ (2006) Acoustic investigation of cold seeps offshore Georgia, eastern Black Sea Mar Geol 231:51-67 doi:10.1016/j.margeo.2006.05.011

Knittel K, Boetius A (2009) Anaerobic oxidation of methane: Progress with unknown process Annual Review of Microbiology 63:311-334 doi:10.1146/annurev.micro.61.080706.093130

Koch S et al. (2015) Gas-controlled seafloor doming Geology 43:571-574 doi:10.1130/G36596.1

Kopf A, Sample JC, Bauer P, Behrmann JH, Erlenkheuser H (1995) Diagenetic carbonates from Cascadia Margin: Textures, chemical composition, and oxygen and carbon stabile isotope signatures. In: Carson, B. et al. (eds.) (1995), Proc. ODP, Sci. Results, 146 (Pt. 1): College Station, TX (Ocean Drilling Program):117-136

Kopf AJ (2002) Significance of mud volcanism Rev Geophys 40 doi:10.1029/2000rg000093

Kvenvolden KA (1988) Methane hydrate - a major reservoir of carbon in the shallow geosphere? Chem Geol 71:41-51

Loher M, Ceramicola S, Wintersteller P, Meinecke G, Sahling H, Bohrmann G (2018) Mud Volcanism in a Canyon: Morphodynamic Evolution of the Active Venere Mud Volcano and Its Interplay With Squillace Canyon, Central Mediterranean Geochemistry, Geophysics, Geosystems:n/a-n/a doi:10.1002/2017gc007166 
Loher $\mathrm{M}$ et al. (in review) Mud extrusion and ring-fault gas seepage - upward branching fluid discharge at a deep-sea mud volcano Sci Rep-Uk

Loher M, Reusch A, Strasser M (2016) Long-term pockmark maintenance by fluid seepage and subsurface sediment mobilization - sedimentological investigations in Lake Neuchâtel Sedimentology 63:1168-1186 doi:10.1111/sed.12255

Long D, Lammers S, Linke P (1998) Possible hydrate mounds within large sea-floor craters in the Barents Sea Geological Society, London, Special Publications 137:223

Luff R, Wallmann K, Aloisi G (2004) Numerical modeling of carbonate crust formation at cold vent sites:significance for fluid and methane budgets and chemosynthetic biological communities Earth Planet Sc Lett 221:337-353

Malinverno A, Ryan WBF (1986) Extension in the Tyrrhenian Sea and shortening in the Apennines as result of arc migration driven by sinking of the lithosphere Tectonics 5:227-245 doi:10.1029/TC005i002p00227

Maltman AJ, Bolton A (2003) How sediments become mobilized Subsurface Sediment Mobilization 216:9-20 doi:10.1144/Gsl.Sp.2003.216.01.02

Marcon Y, Ondréas H, Sahling H, Bohrmann G, Olu K (2014a) Fluid flow regimes and growth of a giant pockmark Geology 42:63-66 doi:10.1130/g34801.1

Marcon Y, Sahling H, Allais A-G, Bohrmann G, Olu K (2014b) Distribution and temporal variation of mega-fauna at the Regab pockmark (Northern Congo Fan), based on a comparison of videomosaics and geographic information systems analyses Marine Ecology 35:77-95 doi:10.1111/maec.12056

Marcon Y, Sahling H, Bohrmann G (2013a) LAPM: a tool for underwater large-area photo-mosaicking Geosci Instrum Method Data Syst 2:189-198 doi:10.5194/gi2-189-2013

Marcon Y, Sahling H, Borowski C, dos Santos Ferreira C, Thal J, Bohrmann G (2013b) Megafaunal distribution and assessment of total methane and sulfide consumption by mussel beds at Menez Gwen hydrothermal vent, based on geo-referenced photomosaics Deep Sea Research Part I: Oceanographic Research Papers 75:93-109 doi:http://dx.doi.org/10.1016/j.dsr.2013.01.008

Matsumoto R (1990) Vuggy Carbonate Crust Formed by Hydrocarbon Seepage on the Continental-Shelf of Baffin Island, Northeast Canada Geochemical Journal 24:143-158

Minelli L, Faccenna C (2010) Evolution of the Calabrian accretionary wedge (central Mediterranean) Tectonics 29 doi:10.1029/2009tc002562

Mozley PS, Burns SJ (1993) Oxygen and Carbon Isotopic Composition of Marine Carbonate Concretions - an Overview J Sediment Petrol 63:73-83

Naehr TH et al. (2007) Authigenic carbonate formation at hydrocarbon seeps in continental margin sediments: A comparative study Deep-Sea Res Pt li 54:1268-1291 doi:10.1016/j.dsr2.2007.04.010

Naudts L, Greinert J, Artemov Y, Beaubien SE, Borowski C, Batist MD (2008) Anomalous sea-floor backscatter patterns in methane venting areas, Dnepr paleo-delta, NW Black Sea Mar Geol 251:253-267

Nikolovska A, Sahling H, Bohrmann G (2008) Hydroacoustic methodology for detection, localization, and quantification of gas bubbles rising from the 
seafloor at gas seeps from the Black Sea Geochem Geophy Geosy 9:Q10010 doi:10.1029/2008GC002118

Nix ER, Fisher CR, Vodenichar J, Scott KM (1995) Physiological ecology of a mussel with methanotrophic endosymbionts at three hydrocarbon seep sites in the Gulf of Mexico Mar Biol 122:605-617

O'Regan M, Forwick M, Jakobsson M, Moran K, Mosher D (2015) Seafloor cratering and sediment remolding at sites of fluid escape Geology 43:895-898 doi:10.1130/G36945.1

Panieri $\mathrm{G}$ et al. (2017) An integrated view of the methane system in the pockmarks at Vestnesa Ridge, $79^{\circ} \mathrm{N}$ Mar Geol 390:282-300 doi:10.1016/j.margeo.2017.06.006

Pape T, Blumenberg M, Seifert R, Egorov VN, Gulin SB, Michaelis W (2005) Lipid geochemistry of methane-seep-related Black Sea carbonates Palaeogeography, Palaeoclimatology, Palaeoecology 227:31-47

Pape T, Kasten S, Zabel M, Bahr A, Abegg F, Hohnberg H-J, Bohrmann G (2010) Gas hydrates in shallow deposits of the Amsterdam mud volcano, Anaximander Mountains, Northeastern Mediterranean Sea Geo-Mar Lett 30:187-206 doi:10.1007/s00367-010-0197-8

Patterson WP, Smith GR, Lohmann KC (1993) Continental Paleothermometry and Seasonality Using the Isotopic Composition of Aragonitic Otoliths of Freshwater Fishes. In: Climate Change in Continental Isotopic Records. American Geophysical Union, pp 191-202. doi:10.1029/GM078p0191

Paull CK et al. (2015) Active mud volcanoes on the continental slope of the Canadian Beaufort Sea Geochem Geophy Geosy 16:3160-3181 doi:10.1002/2015gc005928

Paull CK et al. (1984) Biological communities at the Florida Escarpment resemble hydrothermal vent taxa Science 226:965-967

Peckmann J, Thiel V (2004) Carbon cycling at ancient methane-seeps Chem Geol 205:443-467

Philip BT, Denny AR, Solomon EA, Kelley DS (2016) Time-series measurements of bubble plume variability and water column methane distribution above Southern Hydrate Ridge, Oregon Geochem Geophy Geosy 17:1182-1196 doi:10.1002/2016gc006250

Pierre C (1999) The oxygen and carbon isotope distribution in the Mediterranean water masses Mar Geol 153:41-55 doi:Doi 10.1016/S0025-3227(98)00090-5

Pierre C, Bayon G, Blanc-Valleron MM, Mascle J, Dupre S (2014) Authigenic carbonates related to active seepage of methane-rich hot brines at the Cheops mud volcano, Menes caldera (Nile deep-sea fan, eastern Mediterranean Sea) Geo-Mar Lett 34:253-267 doi:10.1007/s00367-014-03626

Polonia A, Torelli L, Mussoni P, Gasperini L, Artoni A, Klaeschen D (2011) The Calabrian Arc subduction complex in the Ionian Sea: Regional architecture, active deformation, and seismic hazard Tectonics 30 doi:10.1029/2010tc002821

Praeg D, Ceramicola S, Barbieri R, Unnithan V, Wardell N (2009) Tectonically-driven mud volcanism since the late Pliocene on the Calabrian accretionary prism, 
central Mediterranean Sea Mar Petrol Geol 26:1849-1865 doi:10.1016/j.marpetgeo.2009.03.008

Reeburgh WS (1976) Methane Consumption in Cariaco Trench Waters and Sediments Earth Planet Sc Lett 28:337-344 doi:Doi 10.1016/0012$821 \times(76) 90195-3$

Roda C (1964) Distribuzione e facies dei sedimenti Neogenici nel Bacino Crotonese Geol Romana 3:319-366

Römer M, Riedel M, Scherwath M, Heesemann M, Spence GD (2016) Tidally controlled gas bubble emissions: A comprehensive study using long-term monitoring data from the NEPTUNE cabled observatory offshore Vancouver Island Geochem Geophy Geosy 17:3797-3814 doi:10.1002/2016gc006528

Römer M, Sahling H, Pape T, Bahr A, Feseker T, Wintersteller P, Bohrmann G (2012) Geological control and quantity of methane ebullition from a high-flux seep area in the Black Sea - the Kerch seep area Mar Geol 319-322:57-74 doi:10.1016/j.margeo.2012.07.005

Römer M, Sahling H, Pape T, Ferreira CD, Wenzhofer F, Boetius A, Bohrmann G (2014) Methane fluxes and carbonate deposits at a cold seep area of the Central Nile Deep Sea Fan, Eastern Mediterranean Sea Mar Geol 347:27-42 doi:10.1016/j.margeo.2013.10.011

Rossi S, Sartori R (1981) A Seismic-Reflection Study of the External Calabrian Arc in the Northern Ionian Sea (Eastern Mediterranean) Marine Geophysical Researches 4:403-426 doi:10.1007/Bf00286036

Sahling $\mathrm{H}$ et al. (2008) Pockmarks in the Northern Congo Fan area, SW Africa: Complex seafloor features shaped by fluid flow Mar Geol 249:206-225

Sahling $\mathrm{H}$ et al. (2016) Massive asphalt deposits, oil seepage, and gas venting support abundant chemosynthetic communities at the Campeche Knolls, southern Gulf of Mexico Biogeosciences 13:4491-4512 doi:10.5194/bg-134491-2016

Sahling H, Rickert D, Lee RW, Linke P, Suess E (2002) Macrofaunal community structure and sulfide flux at gas hydrate deposits from the Cascadia convergent margin, NE Pacific Mar Ecol Prog Ser 231:121-138

Sassen R, Roberts HH, Aharon P, Larkin J, Chinn EW, Carney R (1993) Chemosynthetic bacterial mats at cold hydrocarbon seeps, Gulf of Mexico continetal slope Org Geochem 20:77-89

Sassen R, Roberts HH, Carney R, Milkov AV, DeFreitas DA, Lanoil BD, Zhang CL (2004) Free hydrocarbon gas, gas hydrate, and authigenic minerals in chemosynthetic communities of the northern Gulf of Mexico continental slope: relation to microbial processes Chem Geol 205:195-217

Sauer S et al. (2017) U-Th chronology and formation controls of methane-derived authigenic carbonates from the Hola trough seep area, northern Norway Chem Geol 470:164-179 doi:10.1016/j.chemgeo.2017.09.004

Sibuet M, Olu K (1998) Biogeography, biodiversity and fluid dependence of deep-sea cold-seep communities at active and passive margins Deep-Sea Research II 45:517-567

Sommer S et al. (2006) Efficiency of the benthic filter: Biological control of the emission of dissolved methane from sediments containing shallow gas 
hydrates at Hydrate Ridge Global Biogeochem Cy 20 doi:10.1029/2004GB002389

Southward EC, Andersen AC, Hourdez S (2011) Lamellibrachia anaximandri n. sp., a new vestimentiferan tubeworm (Annelida) from the Mediterranean, with notes on frenulate tubeworms from the same habitat Zoosystema 33:245-279 doi:doi:10.5252/z2011n3a1

Sultan N et al. (2014) Pockmark formation and evolution in deep water Nigeria: Rapid hydrate growth versus slow hydrate dissolution J Geophys Res-Sol Ea 119:2679-2694 doi:10.1002/2013jb010546

Teichert BMA, Bohrmann G, Suess E (2005) Chemoherms on Hydrate Ridge: Unique microbially-mediated carbonate build-ups growing into the water column Palaeogeography, Palaeoclimatology, Palaeoecology 227:67-85

Teichert BMA, Eisenhauer A, Bohrmann G, Haase-Schramm A, Bock B, Linke P (2003) U/Th systematics and ages of authigenic carbonates from Hydrate Ridge, Cascadia Margin: Recorders of fluid flow variations Geochim Cosmochim Ac 67:3845-3857 doi:10.1016/S0016-7037(03)00128-5

Treude T, Knittel K, Blumenberg M, Seifert R, Boetius A (2005) Subsurface microbial methanotrophic mats in the Black Sea Appl Environ Microb 71:6375-6378 doi:10.1128/Aem.71.10.6375-6378.2005

Ussler W, Paull CK (1995) Effects of Ion-Exclusion and Isotopic Fractionation on Pore-Water Geochemistry during Gas Hydrate Formation and Decomposition Geo-Mar Lett 15:37-44 doi:10.1007/Bf01204496

Van Dijk JP et al. (2000) A regional structural model for the northern sector of the Calabrian Arc (southern Italy) Tectonophysics 324:267-320 doi:10.1016/S0040-1951(00)00139-6

Vogt C, Lauterjung J, Fischer RX (2002) Investigation of the clay fraction $(<2 \mu \mathrm{m})$ of the Clay Minerals Society reference clays Clay Clay Miner 50:388-400 doi:10.1346/000986002760833765

Volgin AV, Woodside JM (1996) Sidescan sonar images of mud volcnoes from the Mediterranean Ridge: possible causes of variations in backscatter intensity Mar Geol 132:39-53

Westaway R (1993) Quaternary Uplift of Southern Italy J Geophys Res-Sol Ea 98:21741-21772 doi:10.1029/93jb01566

Zecchin M, Praeg D, Ceramicola S, Muto F (2015) Onshore to offshore correlation of regional unconformities in the Plio-Pleistocene sedimentary successions of the Calabrian Arc (central Mediterranean) Earth-Sci Rev 142:60-78 doi:10.1016/j.earscirev.2015.01.006

Zeebe RE (2001) Seawater pH and isotopic paleotemperatures of Cretaceous oceans Palaeogeogr Palaeocl 170:49-57 doi:10.1016/S0031-0182(01)00226-7

Zitter TAC, Huguen C, Woodside JM (2005) Geology of mud volcanoes in the eastern Mediterranean from combined sidescan sonar and submersible surveys Deep-Sea Res Pt I 52:457-475 doi:10.1016/j.dsr.2004.10.005 
Video S1: Video of a push-core being taken at Site 1 in soft sediments with intense black patches and white microbial mats. An up-floating flake of white material (at the center of the screen) is interpreted as a piece gas hydrate.

Video S2: Video a push-core being taken at Site 1 in soft sediments with black patches and white microbial mats. Up-floating flakes of white material (close to the push core) are interpreted as a pieces of gas hydrate.

Video S3: Video of a T-stick penetrating a mound at Site 4. Near the site of penetration of the metal rod, disturbances in the water by fluid flow (?Schlieren?) can be made out.

Video S4: Video showing Site 5. An outcropping carbonate slab is colonized by tubeworms and filamentous white microbial mats and forms a ledge. As a result bubbles are released as pulses into the water column.

\section{Highlights}

- Photomosaic- and multibeam-based mapping of cold seeps at Venere mud volcano

- Methane-rich fluids sustain oasis-type ecosystems and carbonate precipitation

- Carbonate self-sealing, rupturing, and collapse influence morphology of the seeps

- Fluid migration, accumulation, and release govern cold seep evolution 